\title{
الكفاءة الخارجية للتعليم الابتدائي في المدارس التابعة لمكتب تعليم شمال المدينة المنورة من وجهة نظر معلمات المرحلة المتوسطة
}

\author{
هيفا لسويعد العوفي \\ ماجستير اقتصاديات التعليم وتخطيطه- وزارة التعليم- المملكة العربية السعودية \\ haifa2359@gmail.com
}




\title{
الكفاءة الخارجية للتعليم الابتدائي في المدارس التابعة لمكتب تعليم شمال المدينة المنورة من وجهة نظر معلمات المرحلة المتوسطة
}

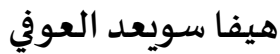 \\ ماجستير اقتصاديات التعليم وتخطيطه- وزارة التعليم- المملكة العربية السعودية \\ haifa2359@gmail.com
}

DOI: https://doi.org/10.31559/EPS2021.10.3.6 2021/7/7 مراستلام البحثة 2021/7/20 قبول البحث: 2021/8/10

هدفت الدراسة التعرف إلى مستوى الكفاءة الخارجية للتعليم الابتدائي (في مادة لغتي الجميلة ومادة الرياضيات) في المدارس التابعة لمكتب تعليم شمال المدينة المنورة من وجهة نظر معلمات المرحلة المتوسطة، واعتمدت الدراسة المنهج الوصفي التحليلي، وتكون مجتمع محت

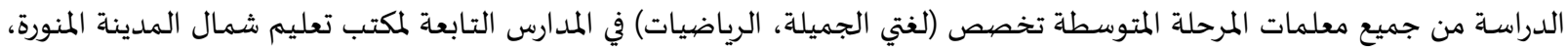
والبالغ عددهن (299) معلمة، وتكونت عينة الدراسة من (248) معلمة من معلمات المرحلة المتوسطة، طبقت عليهم استبانة مكونة من (20)

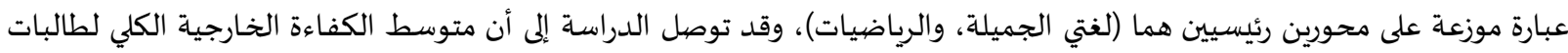

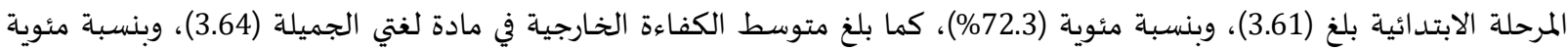

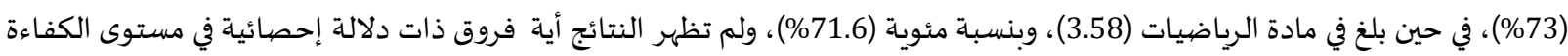

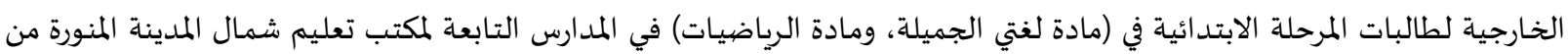

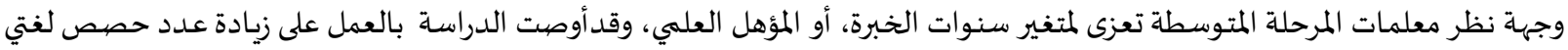

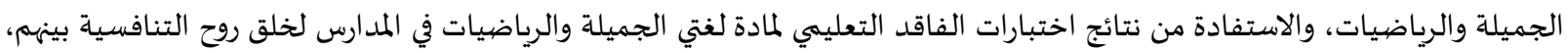
وإنشاء قاعدة بيانات شاملة لرصد المسيرة الدراسية للطلّاب في المراحل التعليمية المختلفة، والعمل على وضع مؤشرات لقياس مخرجات التعليم العام ومراجعتها سنوياً. الكلمات المفتاحية: الكفاءة الخارجية؛ التعليم الابتدائي؛ المدارس؛ المدينة المنورة.

يعد التعليم بوابة التقدم الاجتماعي والاقتصادي والسياسي في أي دولة تسعى إلى الرقي ومواكبة التغيرات المتسارعة؛ ذلك لأن مخرجات قطاع التعليم هي أساس بناء القوى العاملة التي تبنى عليهم ومن أجلهم الخطط الاستراتيجية والتنموية، وبخاصة التهاية في الدول النامية التي تتأثر بالمعرفة ونتائجها، كما تتأثر بالعولمة بشتى صور تأثيراتها، مما يجعل الاهتمام بتطوير قطاع التعليم وتقييمه مطلباً سيادياً ملحاً وبصورة مستمرة. وقد شهد التعليم العام في المملكة العربية السعودية مراحل متعددة في تطويره حيث كانت بدايته تهدف إلى نشر التعليم والتوسع الكمي ثم

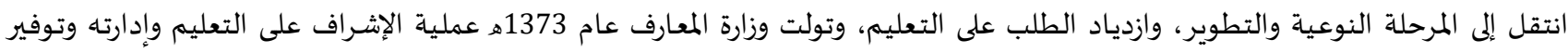

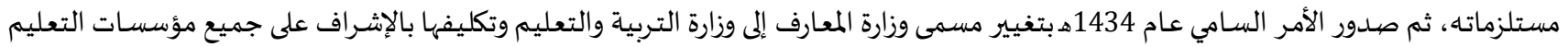


العام، وتقوم الوزارة بعمليات لتطوير للتعليم بشكل عام، وذلك إيمانًا بأهمية مخرجات مراحل التعليم العام في المسـاهمة في بناء المجتمع. (الداود،

وقد تزايد الاهتمام عالمياً منذ ثمانينات القرن الماضي بكفاءة التعليم بغية تحقيق الأهداف والطموحات التي تسعى إليها المجتمعات للقيام

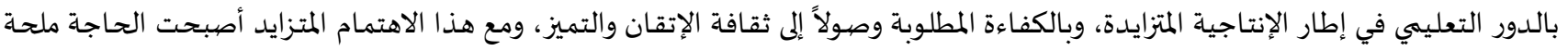

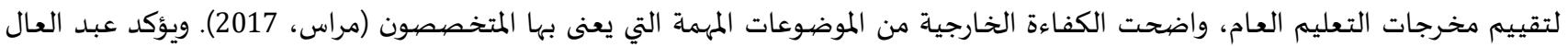
(2010) على أن التوجه نحو الجودة ونشر ثقافتها من أهم متطلبات التعليم، حيث تسعى المؤسسات التعليمية إلى تطوير كفاءتها الداخلية

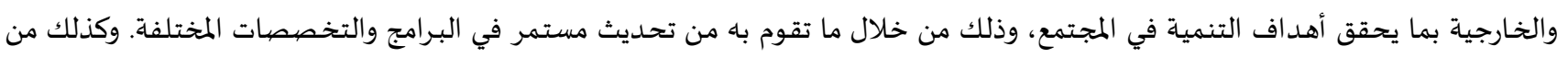

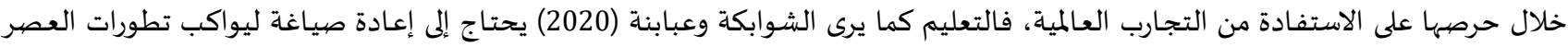
وتحسين مخرجاته وفق الخطط التنموية التي تشهدها المملكة من خلال رؤيتها لرفع مستوى الكفاءة الخـارجية لطلبة التهاية التعليم العام. ويعد موضوع الكفاءة الخارجية (External Efficiency) للتعليم من الموضوعات التي تشغل أذهان المختصين والمفكرين بقضايا التخطيط

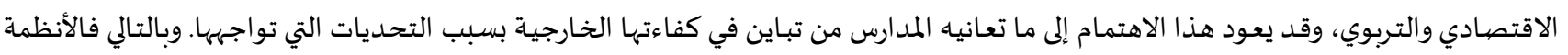
التعليمية معنية بأن تصبح أنظمة متطورة وفعالة من خلال سعيها إلى إنشاء مراكز تعلم وتدريب تستهدف صقدل مهارات الطلبة، بحيث لا تقتصري

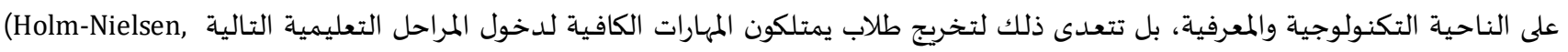

ويعد تعليم المهارات اللغوية لطلاب المرحلة الابتدائية من أهم أهداف التعليم الابتدائي، فقد نص الهدف الثالث من أهداف التعليم في المرحلة

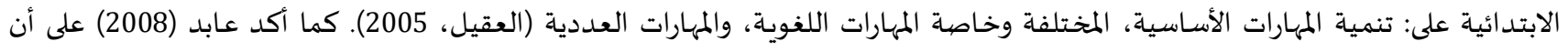

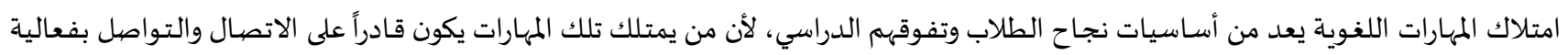

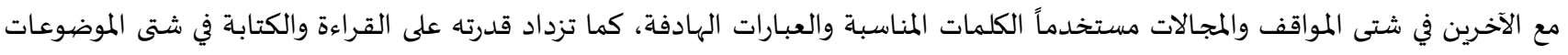

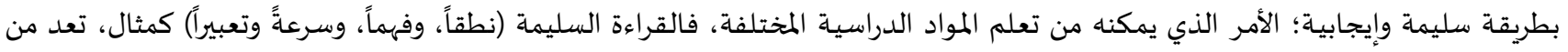

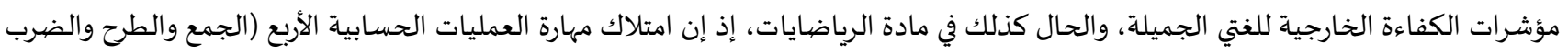
والقسمة) تعد من مؤشرات الكفاءة الخارجية للرياضيات. وعليه تحاول الدراسة الحالية التعرف على مستوى الكفاءة الخارجية للمرحلة الابتدائية بعد التحاق طلبتها بالمدارس المتوسطة التابعة لمكتب تعليم شمات المهاء المدينة المنورة.

الكفاءة الخحارجية:

يشير مفهوم الكفاءة إلى تحقيق أقصى قدر من المخرجات بأدنى قدر من المدخلات، أو الوصول إلى أقصى إنتاج بأقل تكلفة. وفي التعليم توصف

الكفاءة بأنها تحقيق أكبر قدر من المخرجات التعليمية من مستوى معين من المدخلات. (Somi, 2020)

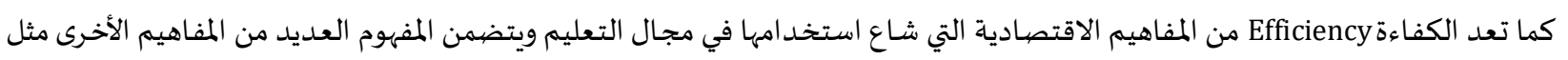

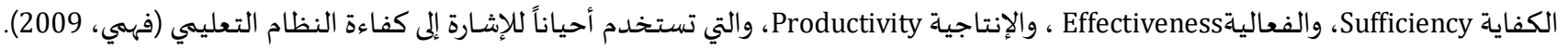

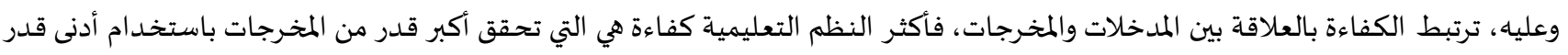
من المدخلات في أقصر وقت وبأكبر قدر من الرضيا والارتياح.

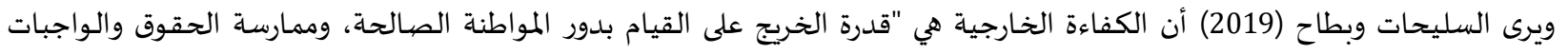

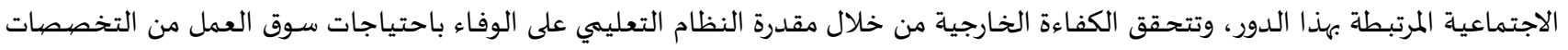

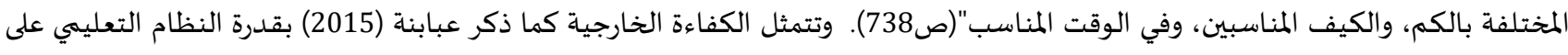

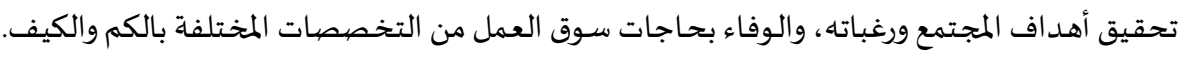
فالكفاءة الخارجية تؤكد على النتائج النهائية البعيدة التي يقدمها النظام التعليمي في مرحلة تعليمية معينة إلى مرحلة لاحقة سواء أكانت داخل

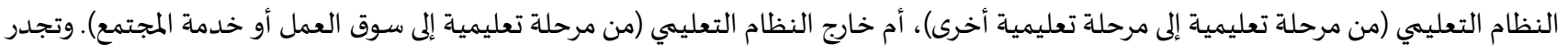
الإشارة إلى وجود صعوبة في قياس الكفاءة الخارجية، وهناك بعض المؤشرات التي تقود إلى إدراك مستوى الكفاءة الخارجية للنظام التعليمي، ويتم

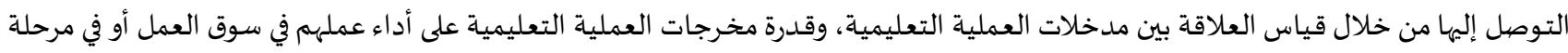

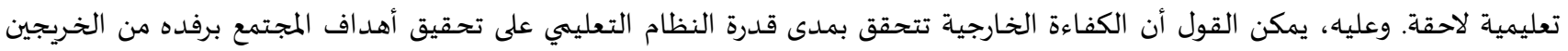

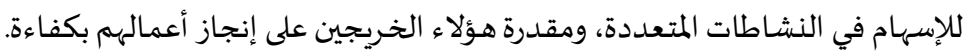

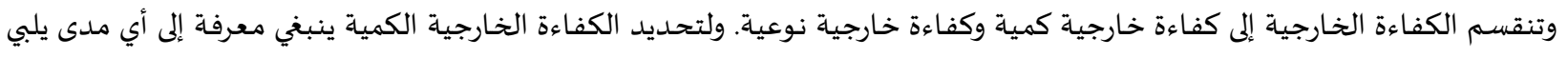

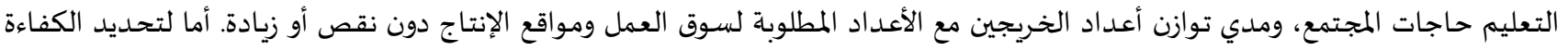


الخـارجية النوعية فينبغي معرفة إلى أي مدي تم إعداد الطلاب للقيام بأدوارهم المستقبلية في المجتمع من خلال تمكنهم من المهارات والكفايات التعليمياة التي يحتاجونها في سوق العمل. ويؤكد يوسف (2009) على أن الكفاءة الخـارجية تمثل قدرة النظام التعليمي على تحقيق أهداف المجتمع الخارجي الذي وجد النظام من أجل

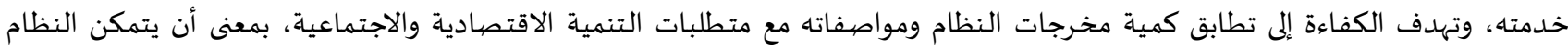
التعليمي من إعداد القوى البشرية العاملة المدربة لتسيير عجلة الاقتصاد وتحقيق التنمية بجميع أوجهها.

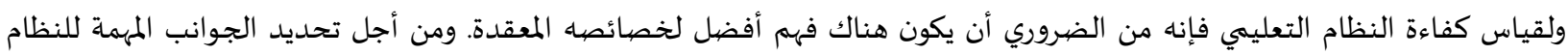

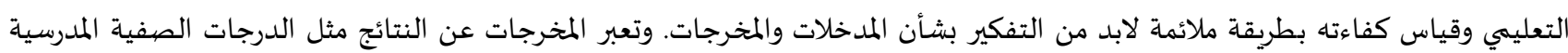
ومعدل الخدمات المتوافرة. (Freitas, Flach, Mattos, Hammes, 2017)

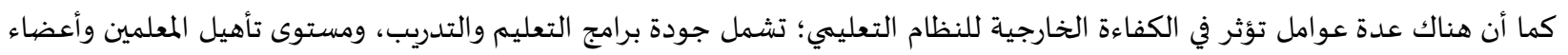

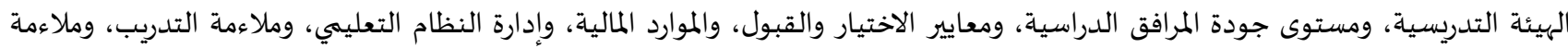

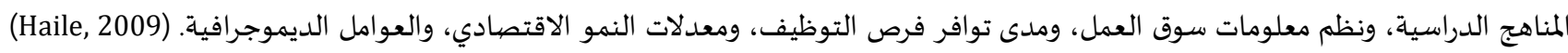
وهناك عوامل أخرى تؤثر في الكفاءة بشكل عام تتمثل في نوع المدارس، ومدى وجود أقسام ووحدات تعليمية فهها، إضافة إلى التركيبة الاجتماعياةالاقتصادية للمجتمع الطلابي، ومؤهلات أعضاء هيئة التدريس، والنمو الاقتصادي للمناطق التي تعمل فيها المؤسسات التعليمية، وجودة الإدارة

التعليمية. (Agasisti, 2017)

وفي حقيقية الأمر، يمكن تحسين كفاءة النظام التعليمي من خلال المزيد من الاهتمام بالنواتج الهـائية التي من المفترض أن تتحقق خلال دورة

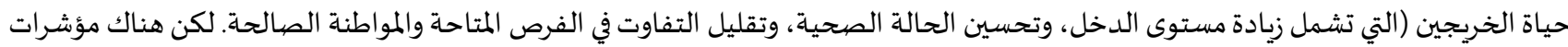

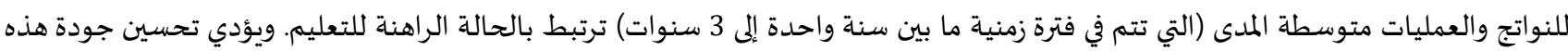

المخرجات والعمليات إلى تحسين النواتج النهائية، التي لا يمكن قياس الكثير منها قبل مرور فترة زمنية معقولة. (Burney, \& Mohammed, 2002)

مهارات اللغة العربية: بذلت وزارة التعليم في المملكة العربية السعودية جهودًا ملموسة لمواكبة متطلبات رؤية المملكة العربية السعودية 2030، حيث أقرت مؤشر تحسين القراءة في عدد من مبادراتها الهادفة إلى رفع مستويات الطلاب ومقدرتهم القرائية؛ بما ينعكس على كفاءتهم العملية بشكل عام، واستنفرت الجهود من أجل الاستعداد الأمثل للاختبارات الدولية، ومنها اختبار المقدرة القرائية لدى الطلاب بيرلز PIRLS. (الشنقيطي، 2020)

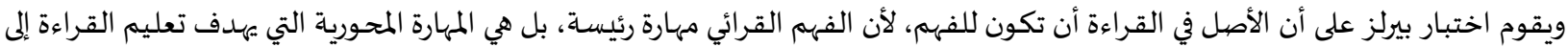

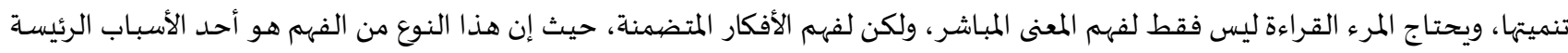

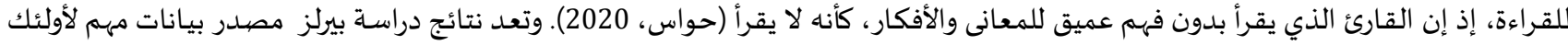

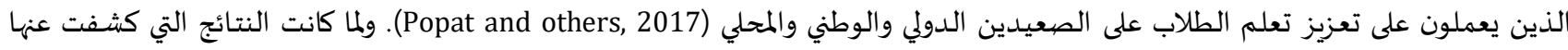

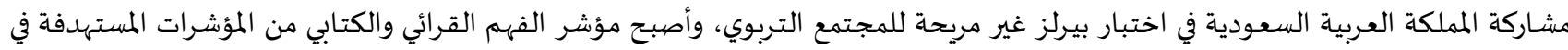

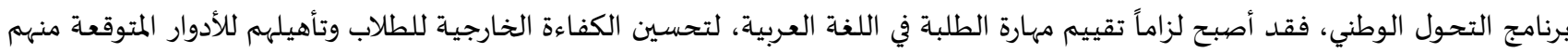

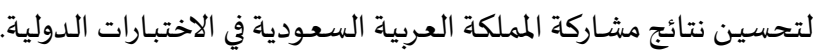

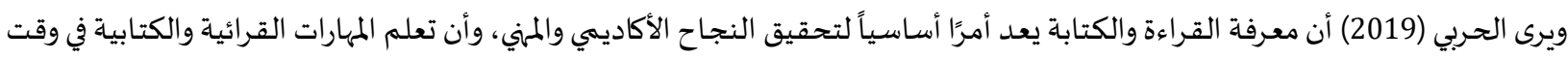

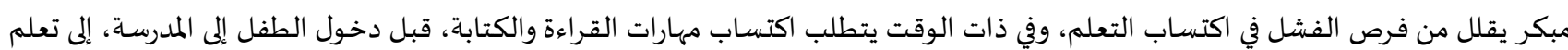

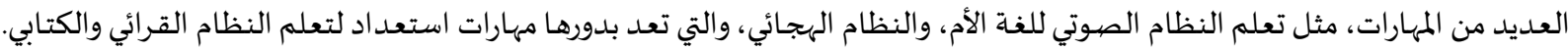

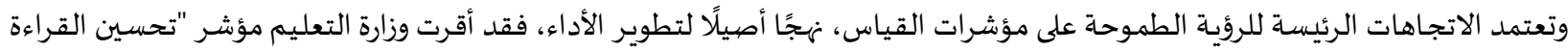

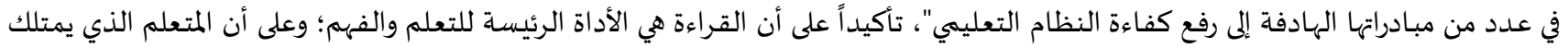

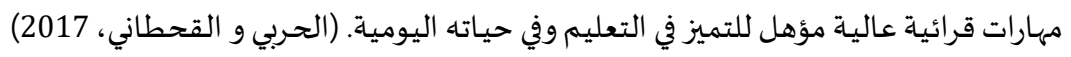

كفاءة تعلم اللغة العربية:

تمثل كفاءة تعلم اللغة العربية أهمية خاصية بالنسبة للطلاب والمربين والقائمين على المناهج الدراسية؛ حيث إن إتقان مهارات اللغة استماعاً

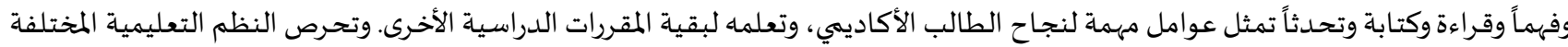

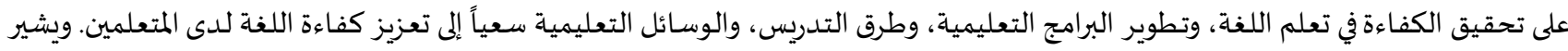
توبي (Tupe, 2015) إلى أن الطفل في عمر 6 إلى 10 سنوات في المرحلة الابتدائية يمتلك قوة استيعاب عالية تمكنها من اكتساب المهارات المتعدددة للغة. وخلال هذه المرحلة العمرية ينبغي توفير فرص لتعلم كثير من اللغات للطفل، لكن عملية تعلم اللغة ينبغي أن تكون طبيعية مثل التعلم بالأداء. كما 
ينبغي أن يكون التدريب هو الطريقة المتبعة في تعليم اللغة لهؤلاء الأطفال؛ حيث يشعر الأطفال بالملل والعزوف عن دراسـة اللغة بسبب ضعف الأداء

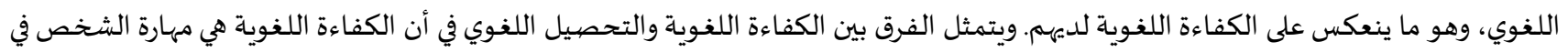

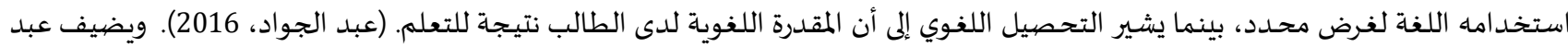
الجواد أن أهم المهارات الأسـاسية التي ينبغي تضمينها في برامج تعليم اللغة الاستماع والقراءة والتحدث واثلة والكتابة، وهي تتضيمن مهارات استقباليه ومهارات إنتاجية للغة. كما يتضح أهمية بناء حصيلة جيدة من المفردات التي تمثل البنية المعرفية اللازمة لفههم اللغة وإنتاجها، مع مراعاة الطريقة

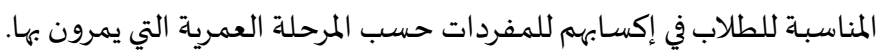

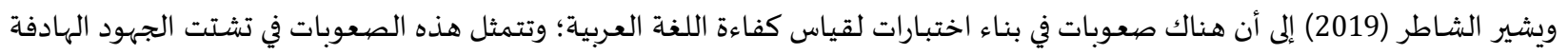

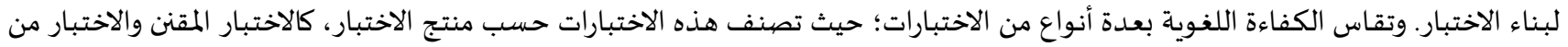

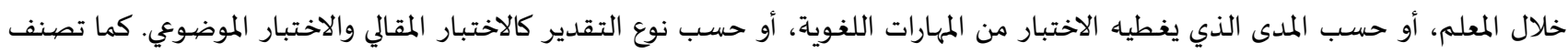

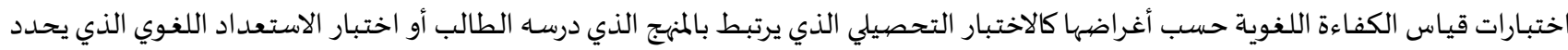
درجة استعد اد الطالب لتعلم اللغة. مهارات الرياضيات: تعمل مادة الرياضيات على إكساب الطالب المفاهيم والكفايات المتعمقة بالأرقام والعمليات الحسابية، والتعرف على أدوات ووحدات القياس

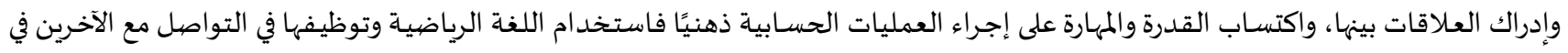

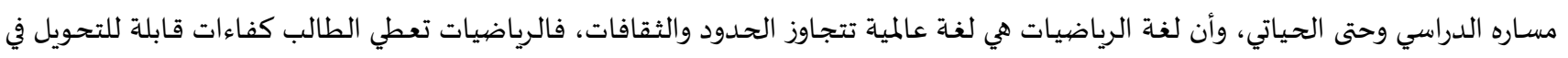

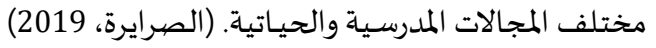

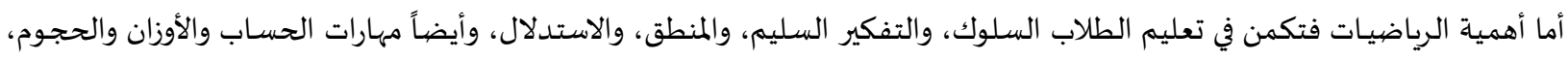
ويعمل تدريس الرياضيات على تكوين اتجاهات إيجابية نحوها وذلك من خلال إتاحة الفرص لهم للتعرف على نشأة هذا العمل، ومساهمته في تشكل

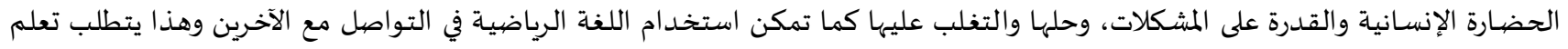

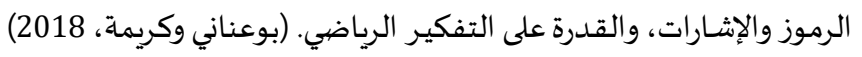

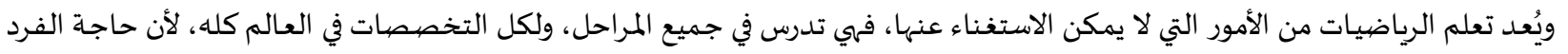

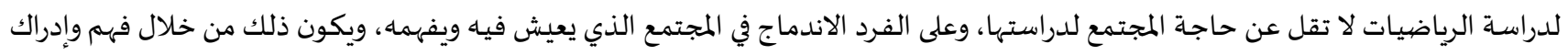

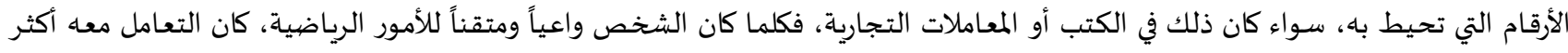

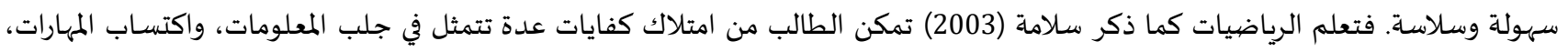

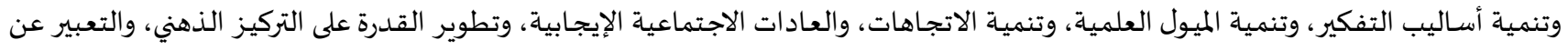

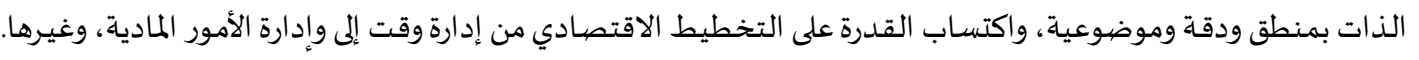

كفاءة تعلم الرياضيات:

لكفاءة تعلم الرياضيات تطبيقات كثيرة تشير إلى قدرة الفرد على الأداء الأكاديمي. وبالرغم من أن المهارات الرياضية يتم التركيز عليها خلال

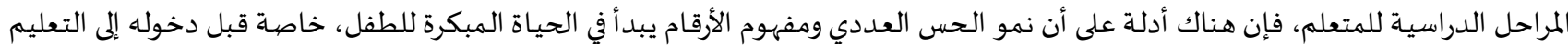
المدرسي الرسمي. (Jimenez \& Saunders, 2019) وعليه، يعد تعلم المهارات الرياضية المبكرة للأطفال منبئاً مهماً بالنجاح الأكاديمي لاحقاً، كما أنها تضيع الأسـاس للمهارات الرياضيات مستقبلاً. وقد أظهرت بحوث كثيرة كما أشار كينك وبوبورا (King \& Purpura, 2021) إلى أن البيئة المنزلية لتعلم

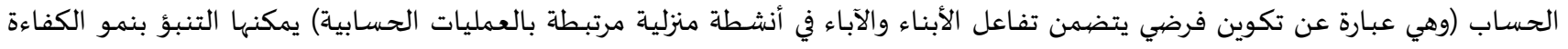

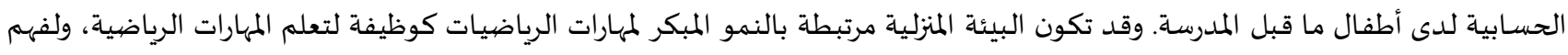

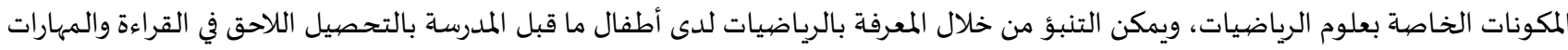

القرائية المبكرة. (Clements, Fuson, \& Sarama, 2017) وعليه، يمكن اعتبار الأنشطة المبكرة لتعليم الأطفال المهارات الحسـابية؛ خاصة تلك الأنشطة التي تحدث خلال التفاعل بين الوالدين والأطفال

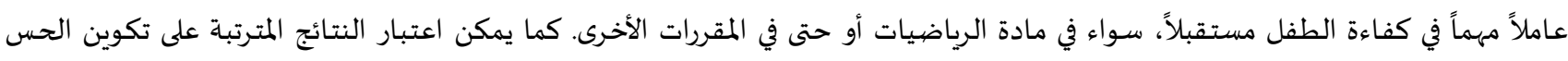
العددي لدى الطفل، واكتساب المهارات الرياضية المبكرة بمثابة الكفاءة الخارجية لتعلم الرياضيات؛ والتي تتمثل في إتقان الطالب للمهارات الرياضياة

في المراحل التعليمياة التالية، وكفاءته في حل المسائل الحسابياة. وتعد معتقدات الطلاب حول مستوى ذكائهم وكفاءتهم في دراسـة الرياضيات عوامل إضافية ينبغي أخذها في الاعتبار في الأنشطة التدريسية اليومياة. وينبغي أن يكون معلمو الرياضيات نماذج لتعليم الطلاب بأن تحصيلههم في الرياضيات يعتمد في الأسـاس على الجهد والمثنابرة أكثر من اعتماده 
(Sekreter, على القدرة الموروثة؛ ومن ثم تكون لدى الطلاب فرصدة لأن يصبحوا متعلمين أكثر كفاءة، ويحققوا أهدافهم بنجاح في تعلم الرياضيات

وبالنظر إلى واقع تدريس الرياضيات في المدارس يتضح أن التدريس لا يزال يركز على تدريس المعلومات، حتى أصبحت المعرفة غاية في حد ذاتها

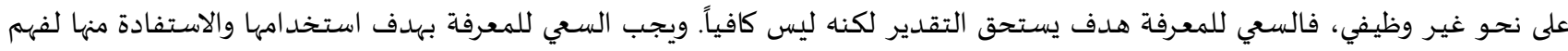
القضايا وتوسيع الخبرة وامتد ادها وعمقها، وهذا لا يتم تلقائياً وإنما لابد من يذل الجهد لتحقيقه. (أبو عطايا وأبو حمادة، 2019)

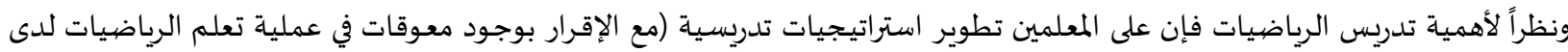

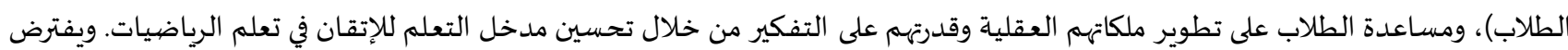

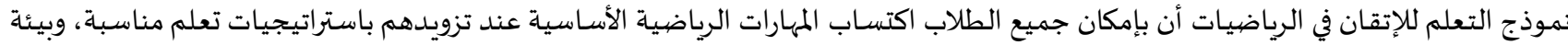

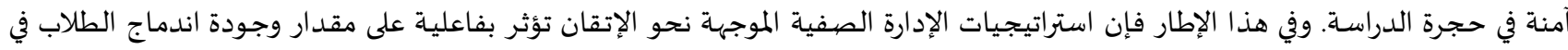
التعلم وكفاءتهم في تعلم الرياضيات، بالإضافة إلى مثابرة الطلاب في استمرار التعلم عندما تكون المهام مثيرة للتحدي. (Sekreter, 2018, p86)

مرحلة التعليم الابتدائي: تكمن أهمية المرحلة الابتدائية في كونها البداية الحقيقة لعملية التنمية الشـاملة لمدارك الطفل روحيًا واجتماعيًا وعقليًا ووجدانيًا وجسميًا،

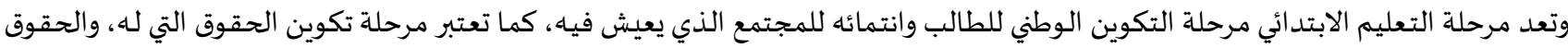
التي عليه، بل يعتبر الهدف الأسمى للمدرسة الحـديثة خاصة الابتدائية حيث إنها لا تقتصر على المعلومات والمعارف بل لابد أن تحقق التوافق

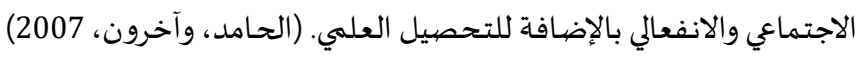
ويرى الساير (2013) أن المرحلة الابتدائية تعد أولى الخطوات على بلى طريق التلمذة الطويل الذي باتهات اليوم لا ينتهي عند حـد معين، بل يستمر في

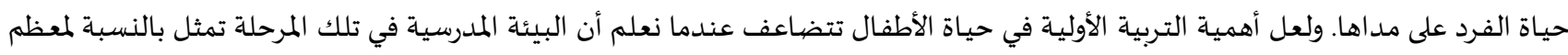

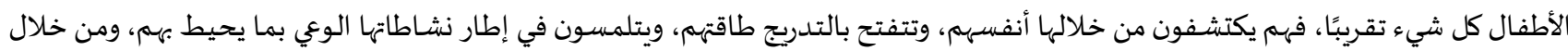

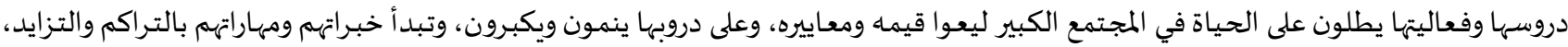

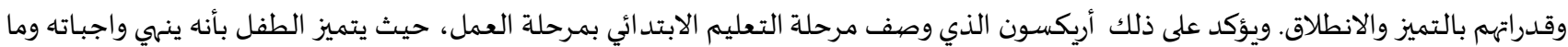

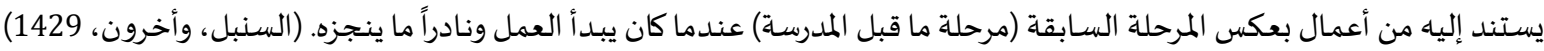
والتعليم الابتدائي في المملكة العربية السعودية يمثل: "المرحلة الأولى من السلم التعليمي والقاعدة الأسـاسية الإجبارية والمجانية والمانية والتي تقبل الأطفال من سن السادسة ولمدة ست سنوات للبنين والبنات دون تمييز وتؤهل التلاميذ لمراحل التعليم التالية وتسـاهم بفاعلية في إعداد الطفل

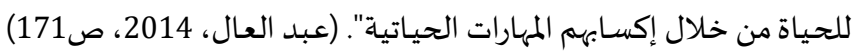
أما المدرسـة الابتدائية فهي: "ذلك النوع من التعليم النظامي الذي يبدأ بها السـم التعليمي الذي يلتحق بهاه الصغار من سن (6- 12 سنة)، أي منذ

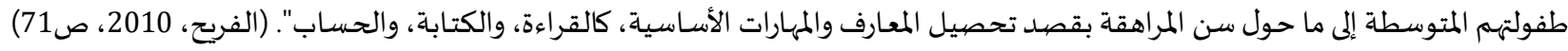

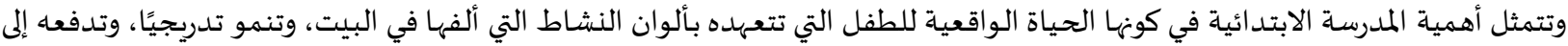

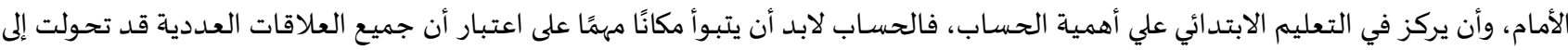

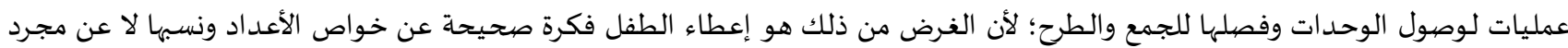
كتابتها، إضـافة إلى الرسم، فقد وجها إليها عناية كبيرة، وكذلك الكتابة التي لا تخرج عن أهها جزء من الرسهم. (الفريح، 2010)

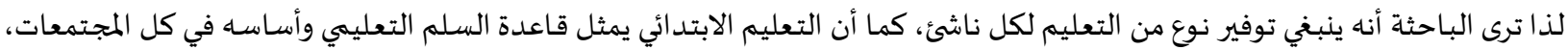
ومن المسلم باه أنه كلما كان أسـاس البناء قويًا وثابتًا كان البناء فوقه أكثر رسـوخًا، ويمثل التعليم الابتدائي الحـد الأدنى الذي لا يمكن الاستغناء عنهـ في إعداد الفرد الصالح.

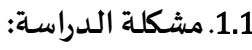

أكدت وثيقة سياسة التعليم في المملكة العربية السعودية على أن المرحلة الابتدائية هي القاعدة التي يرتكز عليها إعداد الناشئين للمراحل التالية من حياتهم، وهي مرحلة عامة معنية بتزويد أبناء الأمة بأسـاسيات العقيدة الصحيحةة، والاتجاهات السليمة والخبرات والمعلومات والمهارات

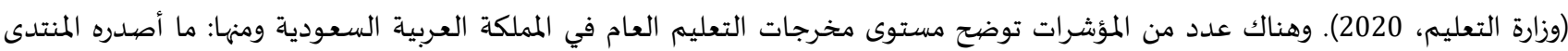
الاقتصادي العالمي في دافوس عام 2019 مؤشرات جودة التعليم لمعظم دول العالم حيث تُقيّم الدول وفق مجمـوعاة من المؤشرات التي توضح

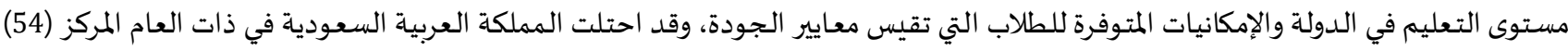
عالميًا والمرتبة السـادسة عربيًا حسب مؤشر جودة التعليم الابتدائي، وشـاركت المملكة العربية السعودية في اختبارات تيمز بالاتجاهات العالمية في التحصيل الدراسي للرياضيات والعلوم، ومن خلال تتبع نتائجها على مدار سنوات (2003، 2007، 2011، 2015) تبين أن 
المملكة العربية السعودية لم تحقق المستوى المطلوب، حيث جاءت نتائج المملكة العربية السعودية في أخر دورة 2015 في مادة الرياضيات للصف

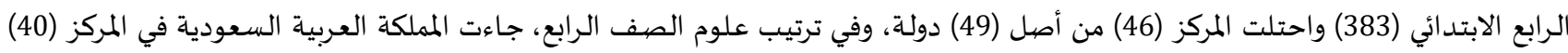

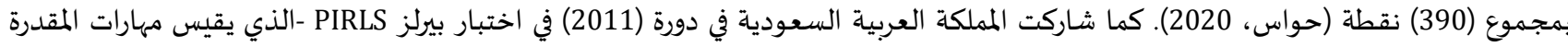

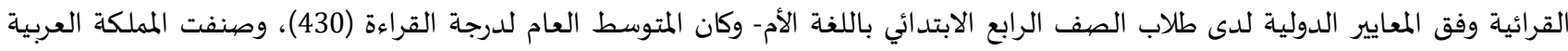
السعودية في المستوى المنخفض (400-475) ضمن الدول الخمس الأقل في قائمة الدول المشاركة (الحربي والقحطاني، 2017). إضافة إلى ما سبق، ومن خلال طبيعة عملز الباحثة ومن خلال موقعها في العمل كقائدة تربوية لمرحلتين في مدرسة (ابتدائية ومتوسطة

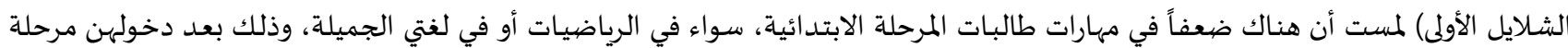
التعليم المتوسطة.

وفي ضوء ما سبق يتضح ضعف مخرجات التعليم العام في المملكة العربية السعودية، مقارنة بالدول المتقدمة، بالرغم من الجههود التي تبذلها المملكة لتطوير التعليم، لذلك نحتاج إلى وقفة لدراسـة الكفاءة الخارجية للتعليم العام خاصية الكفاءة الخارجية لمخرجات مرحلة التعليم الابتدائي،

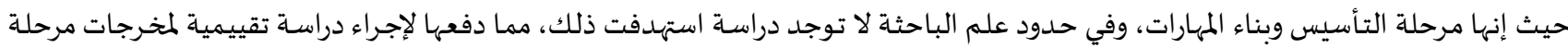
التعليم الابتد ائي للبنات على المدارس التابعة لمكتب تعليم شمال المدينة المنورة من وجهاة نظر معلمات مرحلة التعليم المتوسطة. من هنا جاءت هذهاء

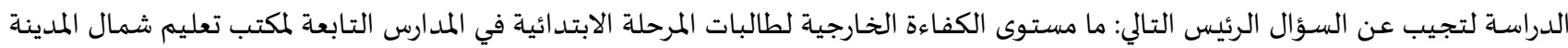

المنورة من وجهة نظر معلمات المرحلة المتوسطة ؟

2.1 2.1 أسئلة الدراسـة:

تم الإجابة عن السؤال الرئيس للدراسة من خلال الإجابة عن الأسئلة الفرعية التالية:

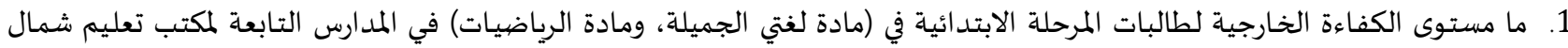

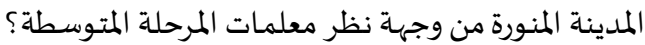

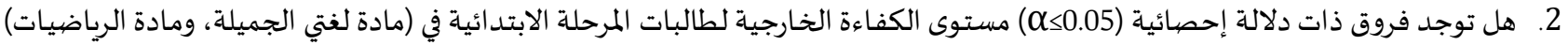
في المد ارس التابعة لمكتب تعليم شمال المدينة المنورة من وجهة نظر معلمات المرحلة المتوسطة تبعاً لمتغيرات (سنوات الخبرة، المؤهل العلمي)؟

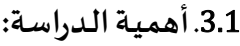

تنبع أهمية الدراسة الحالية من أهمية الموضيوع الذي تطرحها وهو الكفاءة الخـارجية للتعليم العام، فالتعليم العام بالمملكة يحتاج إلى تقييم

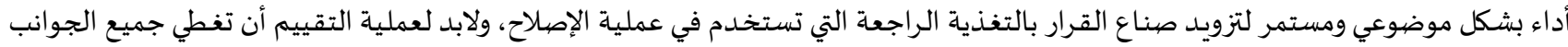

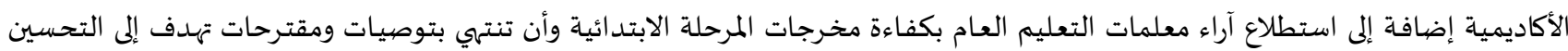

$$
\text { والتطوير، وبشكل عام تجسدت أهمية في بعدين: }
$$

• البعد النظري: تستمد الدراسة أهميتها في هذا البعد من تزامنها مع حاجة صناع القرار ومتخذيه في وزارة التعليم إلى التقدير العلمي للكفاءة

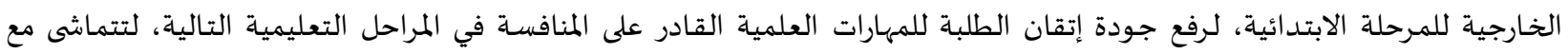
الأهداف الاستراتيجية لرؤية 2030. كما أن الدراسة تسلط الضوهاء على قضية مهمة، وهي الكفاءة الخارجية لطلبة التهانة التعليم العام، واكتسابهم

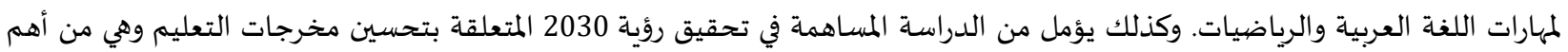
الركائز لتحقيق هذه الأهد اف ومنها التركيز على مهارات الطالب وخاصية اللغة العربية والرياضيات. ه البعد التطبيقي: تأتي هذه الأهمية من خلال الكشف عن مواطن الضيعف والخلل في مخرجات العملية التعليمية ومستوى مهارات الطلبة في

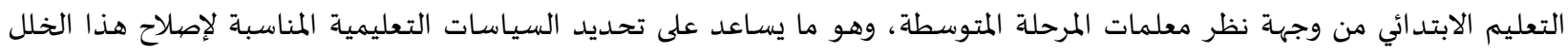
وتطوير العملية التعليمية لنظام التعليم للمرحلة الابتدائية. وقد تفيد نتائج هذه الدراسة في التعرف على مستوى الكفاءة الخارجية لنظام التعليم، لمساعدة المخططين التربوين وراسمي السياسات التعليمية في بناء القرارات التعليمية على أسس علمية سلية سليمة.

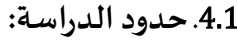

$$
\text { تتمثل حدود الدراسة في الآتي: }
$$

• الحـدود البشرية: معلمات المرحلة المتوسطة (لغتي الجميلة، الرياضيات). • الحـدود المكانية: المدارس المتوسطة التابعة لإشراف مكتب التعليم شمال المدينة المنورة.

• الحـدود الزمنية: في الفترة الزمنية للفصل الدراسي الثاني من عام (1442هـ). 
• الحدود الموضوعية: اقتصرت الدراسة على دراسة الكفاءة الخارجية للتعليم الابتدائي لمادتي الرياضيات ولغتي الجميلة من وجهة نظر معلمات

المرحلة المتوسطة.

5.1

تتبنى الدراسة المصطلحات التالية:

(الكفاءة:

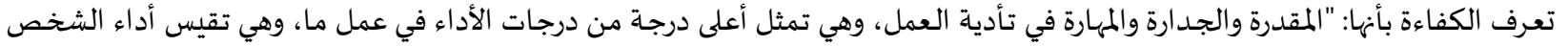

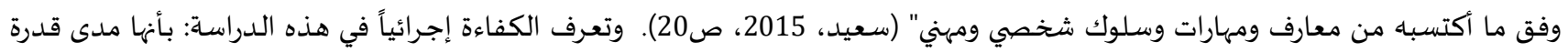
مدارس التعليم العام على تحقيق الدور المطلوب منها في تعليم الطالبات مهارات (لغتي الجميلة، الرياضيات).

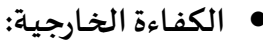

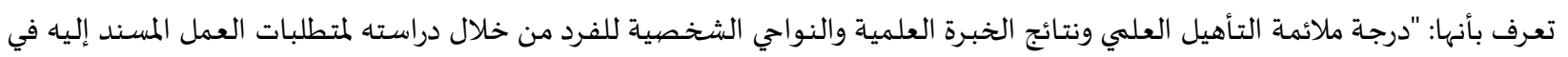

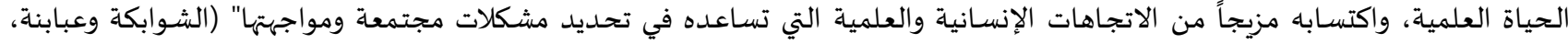

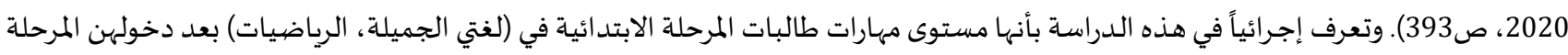
المتوسطة، من وجهة نظر معلمات المرحلة المتوسطة..

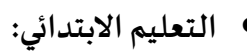

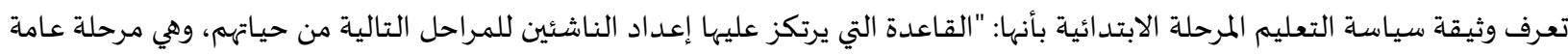

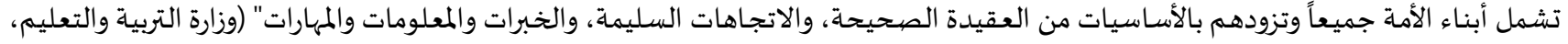

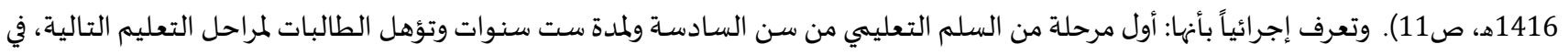
المدارس التابعة لمكتب تعليم شمال المدينة المنورة.

طالبات المرحلة الإبتدائية: تعرف طالبات المرحلة الإبتدائية إجرائياً في هذه الدراسة بأهن الطالبات الماتيات اللواتي أهين دراسة تلك المرحلة، وانتقلن بنجاح إلى المرحلة المتوسطة، ومكثن فيها أكثر من فصل دراسي.

6.1. - الدراسـات السـابقة: بعد اطلاع الباحثة على الأدب النظري في الميدان التربوي المتعلق بمتغيرات الدراسة، والوقوف عند عدد من الدراسات السابقة ذات الصلة

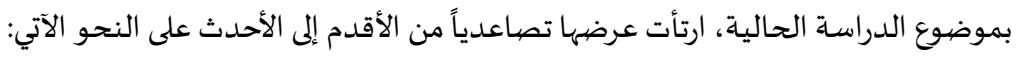

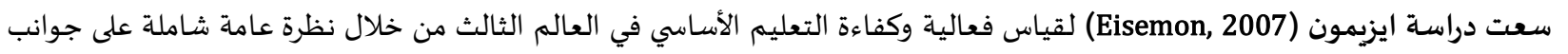

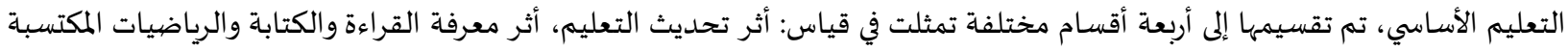

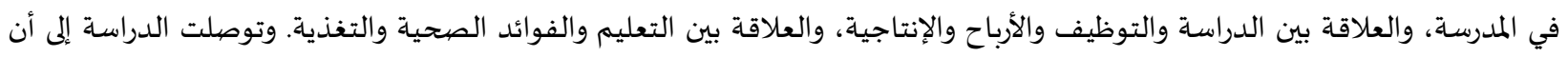

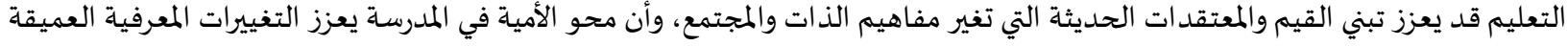

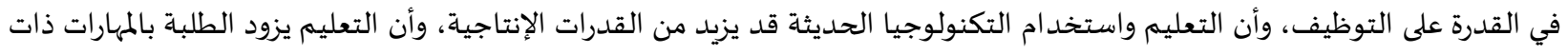

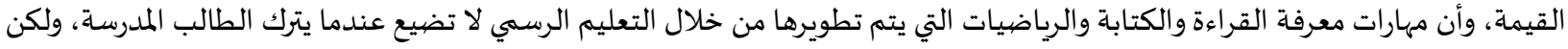

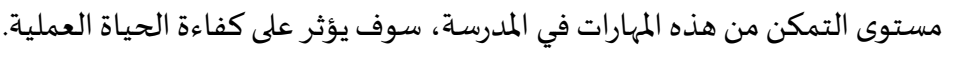

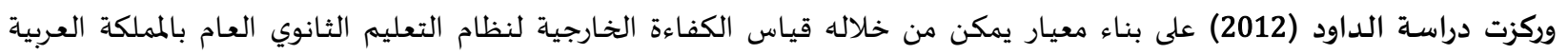

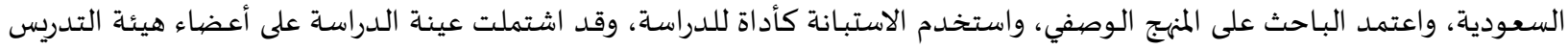

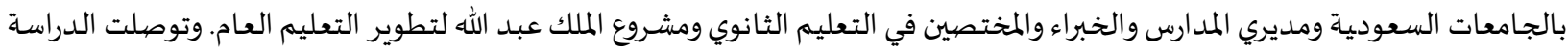

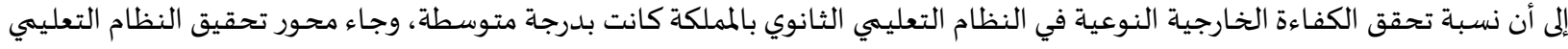

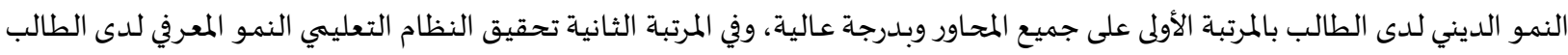
وبدرجة متوسطة، وجاء في الترتيب الثالث تحقيق النظام التعليهي النمو الاجتماعي لدى الطالب، وفي المرتبة الأخيرة تحقيق النظام التيام التعليهي

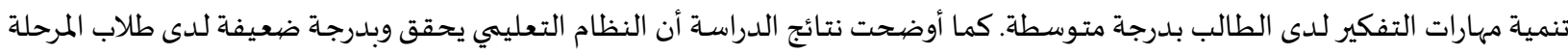

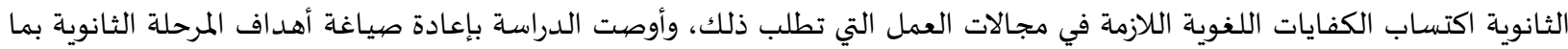


وحاولت دراسـة الساير (2013) تشخيص مستوى تلاميذ الصف الرابع الابتدائي في مهارة فهم المقروء في ضوء منهج لغتي الجميلة. استخدم

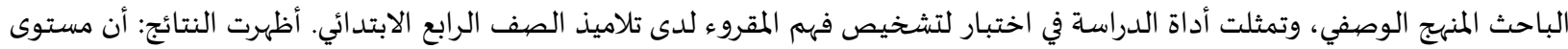
تلاميذ الصف الرابع بمحافظة الرس في فهم المقروء متوسط، حيث جاء المستوى في (مهارة استدعاء التفاصيل واستنتاجها)، ومهارة (تحليل النصوص وفق بنيتها)، ومهارة (تحليل مضمون النص المقروء) متوسطاً، أما مستواهم في مهارة (إدراك الكلمات الجديدة واستراتيجيات الوصول

إليها)، فقد كان منخفضياً.

ودراسة قطب (Qutb, 2016) التي ركزت على الاستثمار العام في التعليم وخلق المهارات والمواقف اللازمة لمستويات أعلى من الإنتاجية والنمو، والتحقق فيما إذا كان سيتم تحقيق هذه الأهداف أم لا، والذي سيعتمد على مقدار الموارد المستثمرة، وعلى الكفاءة التي تدار بها المدخلات.

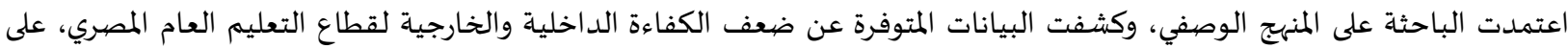
الرغم من الاستثمارات المخصصية له، والكفاءة الخارجية على الرغم من تحقيق العديد من الأهداف المتعلقة بمعدلات الالتحاق والمساواة بين الجنسين، فإنه لا يزال هناك العديد من المؤشرات التي أكدت بشكل غير مباشر وجود ضعف الكئ الكفاءة الخارجية للتعليم العام وفي تطوير قدرات ومهارات ريادة الأعمال للجيل الحالي.

وحاولت دراسـة العتيبي وآخرون (2017) تقصي نوعية التحصيل في مادة الرياضيات لدى طلبة المرحلة الابتدائية وفق مشروع تطوير مناهج الرياضيات في السعودية حسب مجالات المحتوى الرياضي، وتوزيع تحصيل الطلبة في الرياضيات وفق مجالات المحتوى الرياضي والمجالات المعرفية، ومدى اختلاف التحصيل باختلاف النوع الاجتماعي (طالب وطالبة). طبقت الدراسة على (1729) طالبًا وطالبة. ولتحقيق أهداف

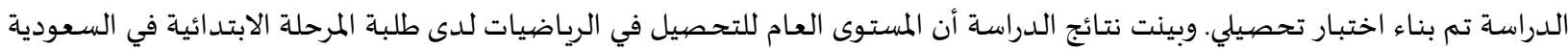

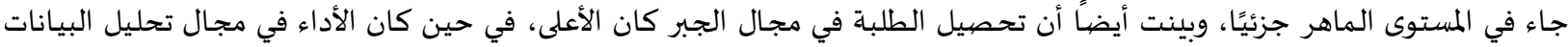

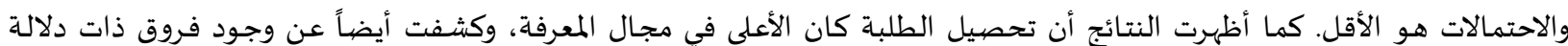
إحصائية في التحصيل بين الذكور والإناث لصالح الذكور.

وهدفت دراسة البرصان (2017) إلى استقصاء مستوى التحصيل في الرياضيات لدى طلبة المرحلة المتوسطة وفق مشروع تطوير مناهج الرياضيات في المملكة العربية السعودية حسب مجالات المحتوى الرياضي، كما استقصت مدرى اختلاف التحصيل التحيل باختلاف النوع الاجتماعي (ذكر وأنثى). وقد بلغ عدد أفراد عينة الدراسـة (1625) طالبًا وطالبة. ولتحقيق أهداف الدراسـة، تم بناء اختبار تحصيلي. وأظهرت نتائج

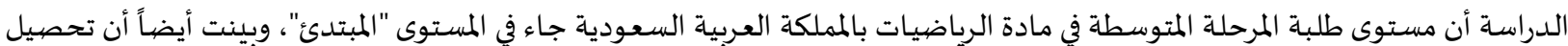
الطلبة جاء في المستوى المبتدئ لجميع مجالات المحتوى الرياضي باستثناء مجال الهندسية الذي جاء في المستوى "الماهر جزئياً"، وكان

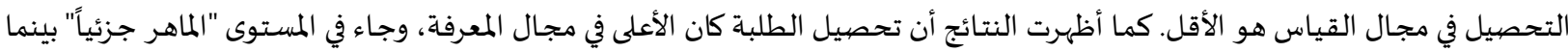

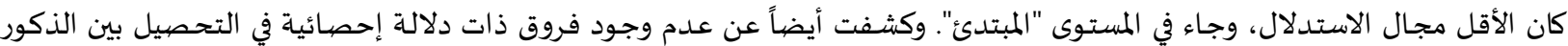
والإناث.

وهدفت دراسة الشهري، وآخرون (2018) إلى تعرف واقع ملائمة مخرجات التعليم في المرحلة الثانوية لمتطلبات سوق العمل السعودي من وجهة نظر أصحاب العمل، استخدمت الدراسة المنهج الوصفي التحليلي، واستخدمت الاستبانة كأداة لها، وتكونت عينة الدراسة من (50) من أصحاب مئاب العمل في مدينة الرياض. وتوصلت الدراسة إلى أن معظم متطلبات العمل تتوافر بدرجة متوسطة لدى خريجي المرحلة الثانوية، وأن الخريج بحاجة إلى التركيز بشكل أكبر على المهارات اللغوية والرياضياة، وأنهم بحاجاة إلى المزيد من التهيئة والفهم لسوق العمل لتحقيق الرضا الوظيفي. كما توصلت نتائج الدراسة إلى أن سوق العمل يتطلب مجموعة من المهارات اللازمة للنجاح فيداه، وأن خريج المرحلة الثانوية بحاجة إلى اكتساب الأخلاقيات المهنية التي تساعده في النجاح من عمله.

وسعت دراسة السليحات وبطاح (2019) إلى وضع تصـور لتحسين الكفـاءة الخـارجية لكليات العلوم التربوية في الجـامعات الأردنية، واعتمـدت

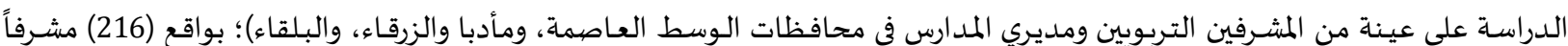
ومشـرفة، و(229) مديرة ومدير في الفصل الأول من العام الدراسي (2015 -2016)، واعتمدت الدراسة المنهج الوصيفي المستيكي التطويري،

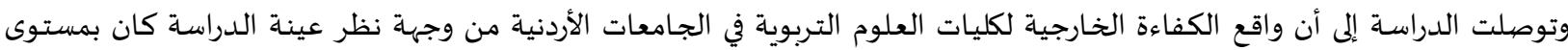
متوسط في مجالات الدراسة ككل، وجاءت بالترتيب: (مجال السمات العامة بمستوى مرتفع، مجال الثقافة بمستوى متوسط، مجال المهارات بمستوى متوسط، مجال الأخلاقيات المهنية بمستوى متوسط، مجال الخدمة الاجتماعية بمستوى منخفض). سعت دراسة الجدعاني (2020) لتعرُّف على مدى امتلاك طلاب المرحلة المتوسطة لمهارات العمليات الرياضية، وعلى مستوى اتجاه طلاب المرحلة المتوسطة نحو الرياضيات، وعلاقة امتلاكهم المهارات الرياضية باتجاههم نحو الرياضيات. واعتمدت الدراسـة على المههج الوصفي،

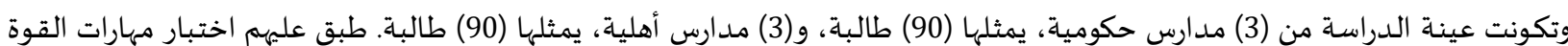


الرياضية، ومقياس الاتجاه نحو الرياضيات. وقد توصلت الدراسة إلى أن درجة امتلاك طلاب الصف الثالث المتوسط لمهارات العمليات

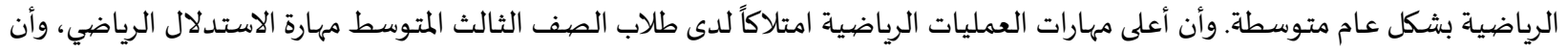

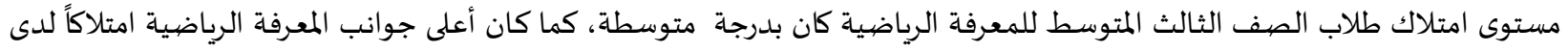
طلاب الصف الثالث المتوسط هو جانب حل المشكلات، كما أظهرت النتائج أن اتجاه طلاب الصف الثالث المتوسط نحو الرياضيات بشكل متول

$$
\text { عام كان متوسطاً. }
$$

من خلال استعراض الدراسات السابقة يتضح أن الدراسة الحالية تتفق مع عدد من الدراسات السابقة في تناول محور الكفاءة في التعليم

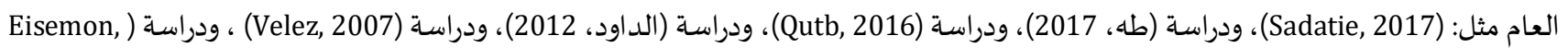

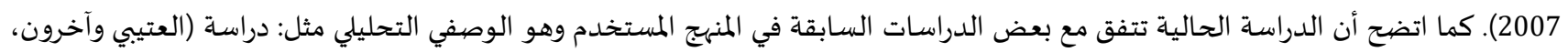

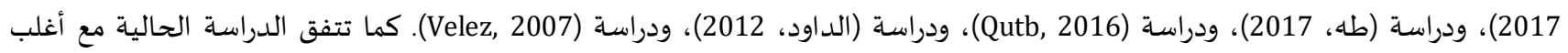

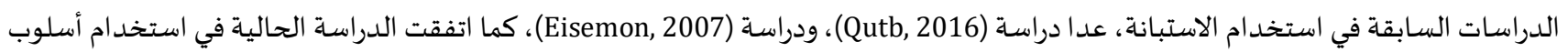
العينة العشوائية مع أغلب الدراسات السابقة.

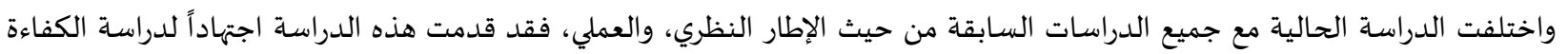

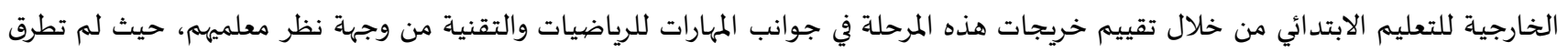

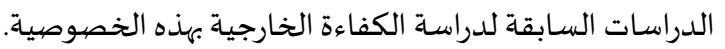

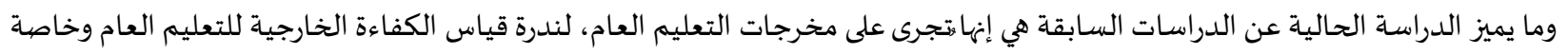

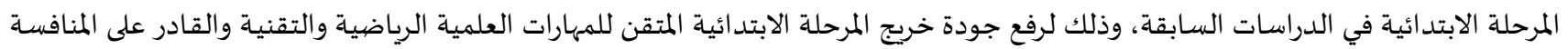
في المراحل التعليمية التالية، وعليه جاءت هذه الدراسة للكشف عن مواطن الضعف والخلل في مخرجات التهات التهات العملية التعليمية ومستوى مهارات الطلبة

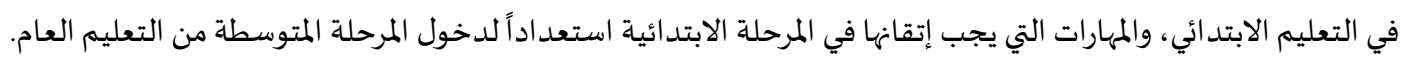

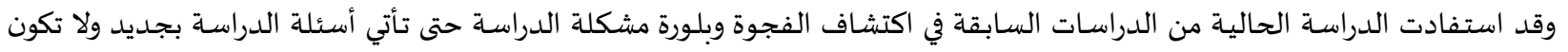
إعادة صياغة لأسئلة أجيب عليها في دراسـات سابقة مشابهة، كما استفادت منها في صياغة الإطار النظري وفى اختيار منهج الدراسة وإعداد أدواد أدوات

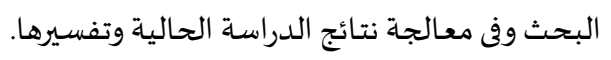

2.

1.2. منهجج الدراسـة:

تبنت الدراسة "المنهج الوصفي التحليلي" لمناسبته لطبيعة الدراسة القائمة، ويُعد المنهج الوصفي التحليلي أحد أهم مناهج البحث العلمي

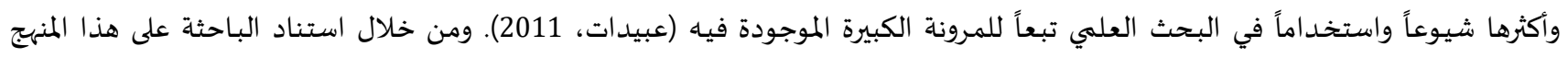
استطاعت دراسـة الواقع بشكل دقيق للغاية، وساعدها في عملية جمع البيانات المتعلقة بقياس الكفاءة الخارجية لمرحلة التعليم الابتدائي، الأمر الذي سهل من وصفها وتبويها وتحليلها بهدف دراستها.

2.2 مجتمع الدراسـة:

تكون مجتمع الدراسـة من معلمات المرحلة المتوسطة (الرياضيات، لغتي الجميلة) للمدارس التابعة لمكتب تعليم شمال المدينة المنورة والبالغ (299) معلمة، بواقع (161) معلمة تخصص لغنتي الجميلة، و (138) معلمة تخصص معدم رياضيات.

3.2. عينة الدراسـة:

تم اختيار عينة البحث بطريقة عشوائية بنسبة مثلت (89\%) من مجتمع البحث، بحيث يكون عدد المعلمات (266) معلمة من أصل (299)

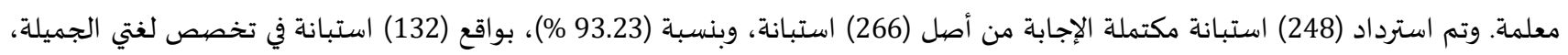
و(116) استبانة في تخصص الرياضيات.

4.2 الوصف الإحصيائي للعينة:

يوضيح الجدولان (1، 2) وصفاً إحصيائياً لعينة الدراسة من حيث سنوات الخبرة، والمؤهل العلمي. 
جدول (1): خصائص عينة الدراسة من حيث الخبرة

\begin{tabular}{|c|c|c|c|c|c|}
\hline \multicolumn{2}{|c|}{ الرياضيات } & \multicolumn{2}{|c|}{ لغتي الجميلة } & \multirow[t]{2}{*}{ المستويات } & \multirow[t]{2}{*}{ 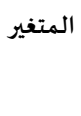 } \\
\hline النسبة (\%) & التكرار & النسبة (\%) & التكرار & & \\
\hline 27.6 & 32 & 21.2 & 28 & أقل من خمس سنوات & الخبرة \\
\hline 26.7 & 31 & 34.8 & 46 & من 5 إلى أقل من 10 سنوات & \\
\hline 20.7 & 24 & 21.2 & 28 & من 10- إلى أقل من 15 سنة & \\
\hline 25.0 & 29 & 22.7 & 30 & 15 سنة فأكثر & \\
\hline$\% 100$ & 116 & $\% 100$ & 132 & المجموع & \\
\hline
\end{tabular}

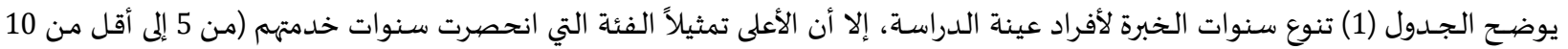

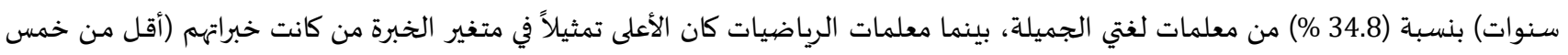

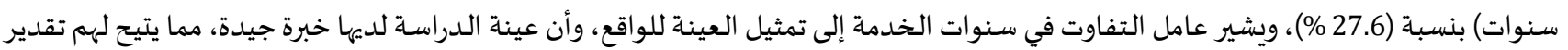
مستوى مهارات الطالبات خريجات المرحلة الابتدائية. جدول (2): خصائص عينة الدراسة من حيث المؤهل العلمي

\begin{tabular}{|c|c|c|c|c|c|}
\hline \multicolumn{2}{|c|}{ الرياضيات } & \multicolumn{2}{|c|}{ لغتي الجميلة } & \multirow{2}{*}{ المستويات } & \multirow[t]{5}{*}{ المؤهل } \\
\hline النسبة (\%) & التكرار & النسبة (\%) & التكرار & & \\
\hline 92.2 & 107 & 90.2 & 119 & بكالوريوس & \\
\hline 7.8 & 9 & 9.8 & 13 & ماجستير فأعلى & \\
\hline 100.0 & 116 & $\% 100$ & 132 & المجموع & \\
\hline
\end{tabular}

يوضح جدول (2) أن أكبر نسبة من أفراد العينة من حملة الدرجة العلمية (بكالوريوس) بنسبة (90.2 \%) بالنسبة لمعلمات لغتي الجميلة وأن

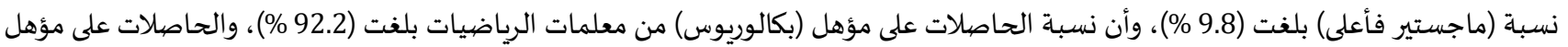

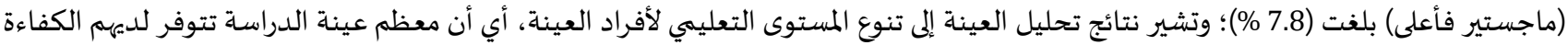

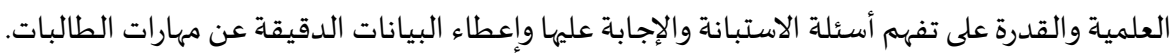

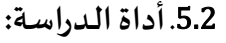

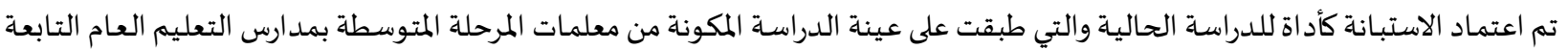

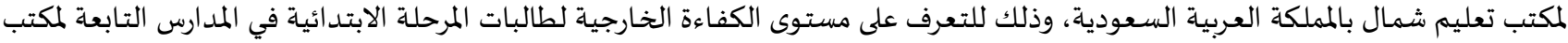

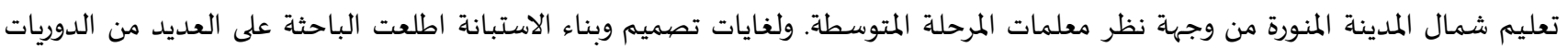
والمجلات والأبحاث والدراسات السابقة ذات الصلة بمشكاية الماتلة الدراسة الحالية كدراسة ايزيمون (Eisemon, 2007)، ودراسة (الداود، 2012)، ودراسة

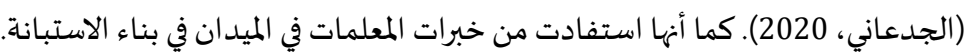

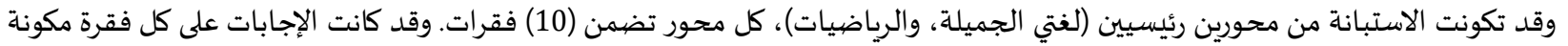

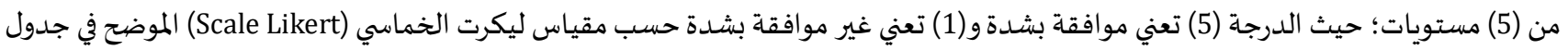

جدول (3): مقياس ليكرت الخماسي المستخدم في الدراسة

\begin{tabular}{|c|c|c|c|c|c|}
\hline غير مو افقة بشدة & & & & مو افقة بشدة & التصنيف \\
\hline 1 & 2 & 3 & 4 & 5 & الدرجة \\
\hline من 1 - إلى أقل من 1.80 & من 1.80 إلى أقل من 2.60 & من 2.60 إلى أقل من & من 3.40 إلى أقل من & من 4.20 إلى 5 & متوسط الدرجة \\
\hline ضيف جداً & ضعيف & متوسط & 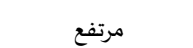 & مرتفع جداً & التقدير \\
\hline
\end{tabular}


1.5.2.الخصبائص السيكومترية للأداة:

تم التأكد من الخصائص السيكومترية بطريقتين هما: الصدق الظاهري والصدق الداخلي (صدق البناء)، وثبات الاستبانة من خلال صدق التهاق

$$
\text { الاتساق الداخلي (الثبات). }
$$

مالصيدق الظاهري للأداة:

تم التحقق من صدق الأداة بعرضها في صورتها الأولية على (13) محكم من أعضياء هيئة التدريس بجامعات مختلفة. وقد أعدت الباحثة استمارة لاستطلاع آراء المحكمين حول مدى قياس العبارة لمتغيرات محوري الدراسة، والتعديل المناسب الذي يراه المحكم على العبارة، ومدى ارتباط عبارات

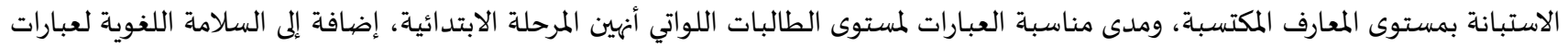
الاستبيان. وفي ضوء التعديلات التي أبداها المحكمون قامت الباحثة بتعديل صياغة بعض العبارات لتصبح أكثر وضوحاً وملاءمة لقياس ما وضعت من

أجلها.

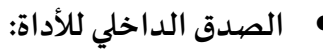

بعد التأكد من الصددق الظاهري لأداة الدراسة قامت الباحثة بتطبيقها على عينة استطلاعية عشوائية قوامها (20) معلمة من خارج عينة

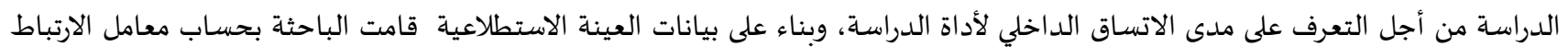
بيرسون لمعرفة الصيدق الد اخلي للإستبانة حيث تم حساب معامل الارتباط بين درجة كل عبارة من عبارات الاستبانة بالدرجة الكلية للمحور الذي تنتمي إليه العبارة كما هو موضسح في الجدول (2) التالي:

جدول (4): معاملات ارتباط بيرسون لعبارات كل محور بالدرجة الكلية للمحور

\begin{tabular}{|c|c|c|c|c|c|}
\hline \multicolumn{3}{|c|}{ محور الرياضيات } & \multicolumn{3}{|c|}{ محورلغتي الجميلة } \\
\hline مستوى الدلالة & معامل الارتباط & رقم العبارة & مستوى الدلالة & معامل الارتباط & رقم العبارة \\
\hline 0.001 & $0.619^{* *}$ & 1 & 0.001 & $0.772^{* *}$ & 1 \\
\hline 0.00 & $0.880^{* *}$ & 2 & 0.001 & $0.876^{* *}$ & 2 \\
\hline 0.00 & $0.794^{* *}$ & 3 & 0.00 & $0.766^{* *}$ & 3 \\
\hline 0.00 & $0.805^{* *}$ & 4 & 0.000 & $0.773^{* *}$ & 4 \\
\hline 0.002 & $0.619^{* *}$ & 5 & 0.00 & $0.856^{* *}$ & 5 \\
\hline 0.001 & $0.652^{* *}$ & 6 & 0.001 & $0.746^{* *}$ & 6 \\
\hline 0.001 & $0.674^{* *}$ & 7 & 0.002 & $0.844^{* *}$ & 7 \\
\hline 0.00 & $0.780^{* *}$ & 8 & 0.000 & $0.767^{* *}$ & 8 \\
\hline 0.00 & $0.868^{* *}$ & 9 & 0.008 & $0.688^{* *}$ & 9 \\
\hline 0.00 & $0.744^{* *}$ & 10 & 0.001 & $0.862^{* *}$ & 10 \\
\hline
\end{tabular}

* * الارتباط دال إحصائياً عند مستوى دلالة (م=0.01)

يتضح من جدول (4) أن قيم معامل ارتباط كل عبارة من العبارات مع محاورها موجبة ودالة إحصائياً عند مستوي الدلالة (0.01) فأقل مما يدل

على صدق اتساقها مع محاورها.

2.5.2 ثبات الأداه:

يقصد بثبات أداة الدراسـة أن تعطى نفس النتيجة لو تم إعادة توزيعها أكثر من مرة، وتحت نفس الظروف والشروط، أو بعبارة أخرى أن ثبات

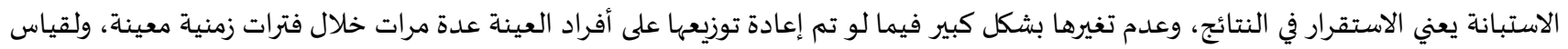

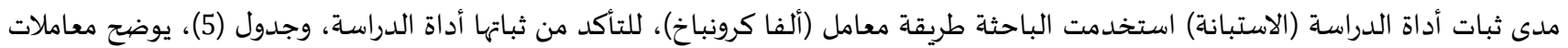
الثبات المحسوباة. جدول (5): معامل ثبات ألفا كرونباخ لمحاور الدراسة

\begin{tabular}{|c|c|c|}
\hline معامل ثبات ألفا- كرونباخ & عدد العبارات & محاور الاستبيانة \\
\hline 0.867 & 10 & لغتي الجميلة \\
\hline 0.832 & 10 & الرياضيات \\
\hline
\end{tabular}

يوضح جدول (5) ثبات أداة الدراسة بطريقة ألفا كرونباخ Cronbach's alpha، قد بلغ الثبات الكلي لمحور لغتي الجميلة (0.867)، وهو معامل ثبات مرتفع ومناسب لأغراض الدراسة، وبلغ الثبات الكلي لمحور الرياضيات (0.832)، وهو معامل ثبات مرتفع ومناسب لأغراض الدراسة، وهي نسبة ثبات عالية مما يشير إلى تمتع الاستبانة بالثبات. وبذلك تكون الباحثة قد تأكدت من صدد استبانة الدراسة وثباتها مما يؤكد صحة الاستبانة وجاهزيتها لتحليل النتائج للإجابة عن أسئلة

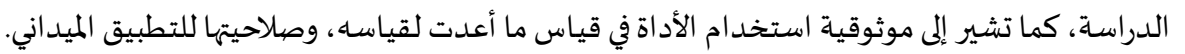


3. نتائج الدراسة ومناقشتها:

تم عرض النتائج ومناقشتها وفقاً لأسئلة الدراسة ومحوريها (لغتي الجميلة، الرياضيات) على النحو التالي:

1.3. النتائج المتعلقة بالسؤال الأول والذي نصها: "ما مستوى الكفاءة الخارجية لطالبات المرحلة الابتدائية في (مادة لغتي الجميلة، ومادة

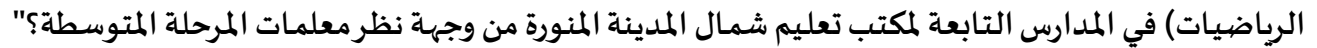

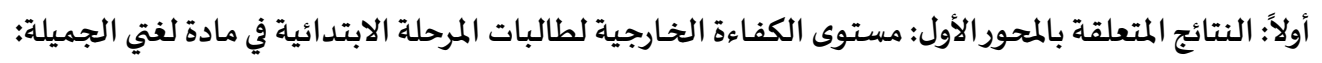

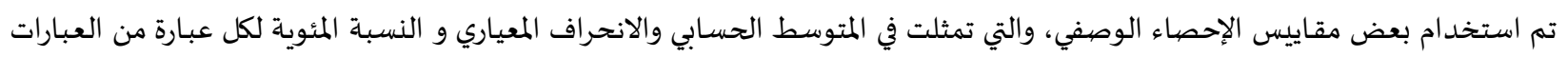

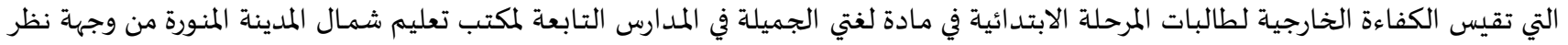
معلمات المرحلة المتوسطة وجدول (6) يبين ذلك.

\begin{tabular}{|c|c|c|c|c|c|c|}
\hline التقدير & الترتيب & المئسبة & المتوسابي & المعياري & 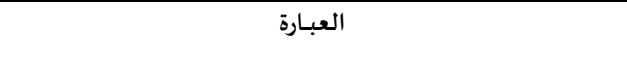 & $\hat{5}$ \\
\hline 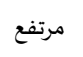 & 5 & $74.8 \%$ & 3.742 & 0.6837 & تستطيع الطالبة القراءة اللغوية السليمة نطقاً. & 1 \\
\hline 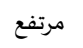 & 1 & $78.2 \%$ & 3.909 & 0.7357 & تستطيح الطالبة كتابة كلمات مختومة بتاء مفتوحة. & 2 \\
\hline 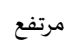 & 9 & $68.5 \%$ & 3.424 & 0.8391 & تستطيح الطالبة كتابة كلمات مختومة بتاء مربوطة. & 3 \\
\hline 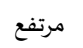 & 3 & $77.1 \%$ & 3.856 & 0.8921 & تميز الطالبة نوع الكلمة (اسم، فعل، حرف). & 4 \\
\hline 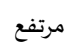 & 4 & $76.1 \%$ & 3.803 & 0.8510 & تفرق الطالبة بين الجملة الإسمية والجملة الفعلية. & 5 \\
\hline 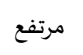 & 6 & $70.8 \%$ & 3.538 & 0.8234 & تتعرف الطالبة على أدوات الفعل المضارع وعلاماته & 6 \\
\hline 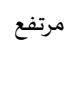 & 2 & $77.6 \%$ & 3.879 & 0.9166 & والتأنيث الطالبة تمييز الأسماء من حيث الإفراد والجمع والتذكير & 7 \\
\hline 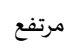 & 8 & $68.6 \%$ & 3.432 & 0.9180 & تكتب الطالبة كلمات تحتوي همزة وصل، وهمزة قطع. & 8 \\
\hline متوسط & 10 & $67.7 \%$ & 3.386 & 0.9300 & تقرأ الطالبة نصوصاً لغوية مع مراعاة الوقف والوصل. & 9 \\
\hline 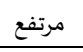 & 7 & $70.3 \%$ & 3.515 & 0.9036 & تتعرف الطالبة على الفاعل بعلامته الفرعية. & 10 \\
\hline \multicolumn{2}{|c|}{$73.0 \%$} & $\% 73$ & 3.648 & 0.4269 & المعدل العام لمحور لغتي الجميلة & \\
\hline
\end{tabular}

يتضح من الجدول (6) أن متوسط الكفاءة الخارجية لطالبات المرحلة الابتدائية في مادة لغتي الجميلة تراوحت بين (3.386- 3.909) وفق مقياس

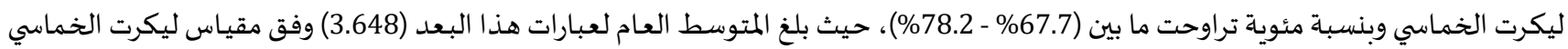

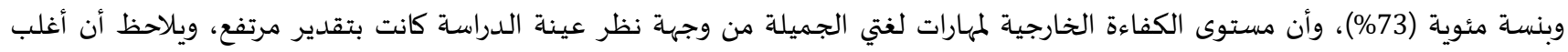

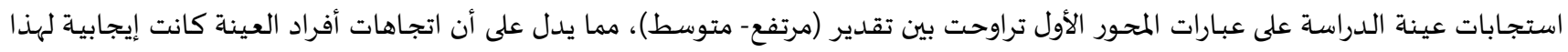

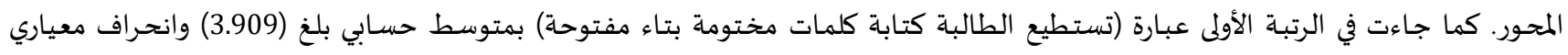

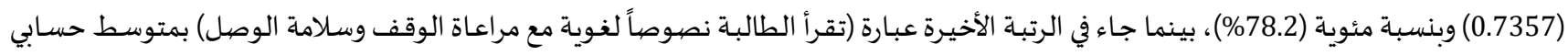
بلغ (3.386) وبانحراف معياري (0.9300) وبنسبة فينسبة مئوية (67.7\%).

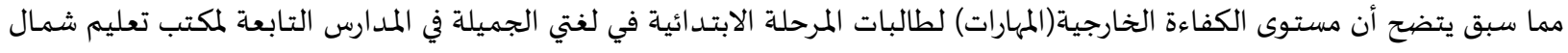

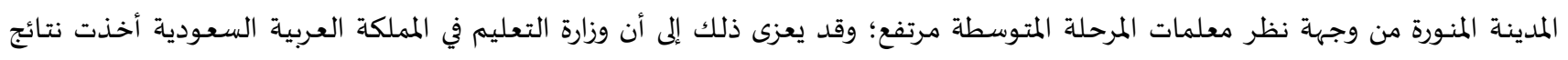

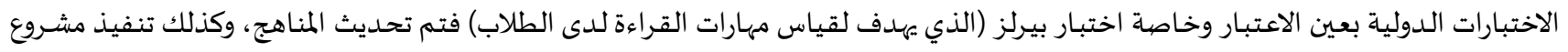

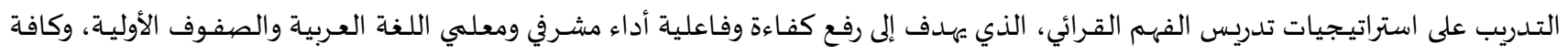

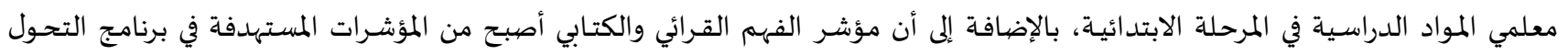

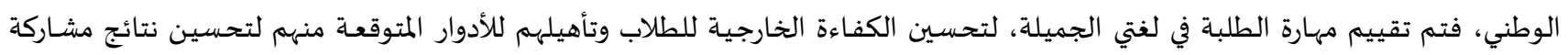

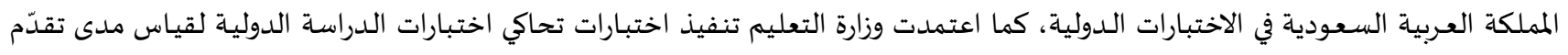

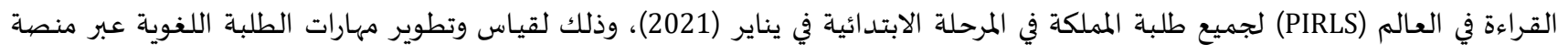

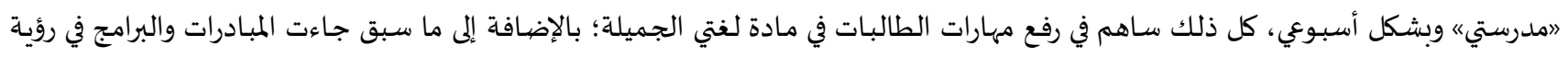

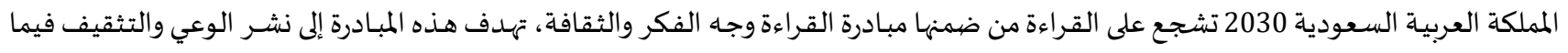

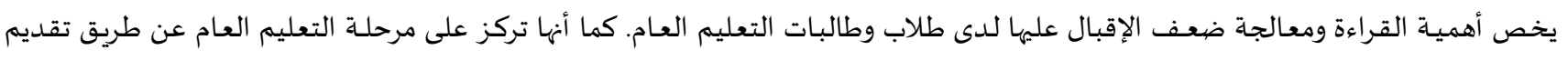

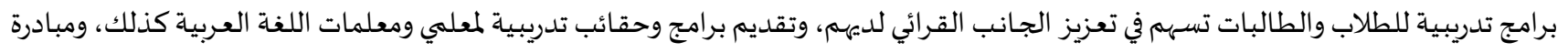


تطوير اللغة العربية التي تهدف إلى تطوير تعليم وتعلم اللغـة العبية في المرحلة الابتدائية في مجالات القراءة والكتابة والمهارات اللغوية الأسـاسية

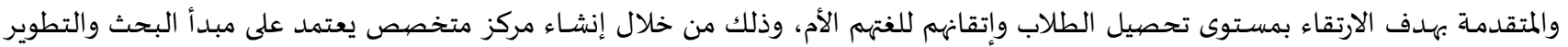

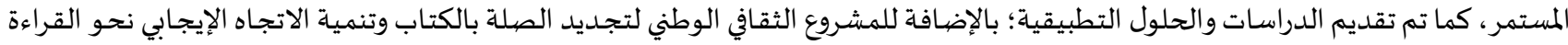

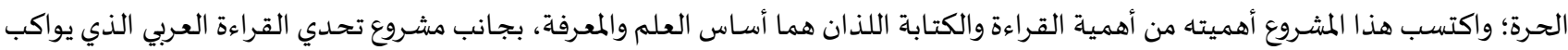

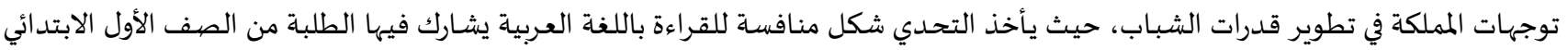

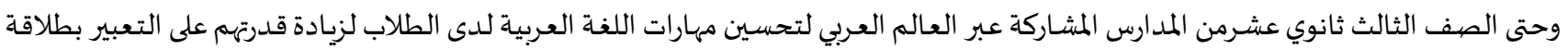

وقد اختلفت هذه النتيجة مع بعض نتائج الدراسات السابقة ومنها: دراسـة الشهري وآخرون(2018) التي أظهرت أن المهارات اللغوية لدى

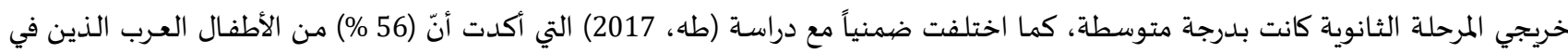

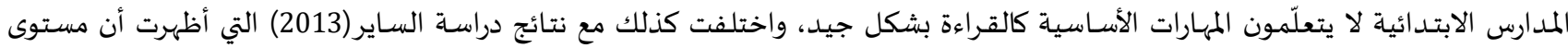
تلاميذ الصف الرابع بمحافظة الرس في فهم المقروء تتراوح بين متوسط وضعيف، حيث جاء المستوى في (مهارة استدعاء التفاصيل واستنتاجهاءها)، ومهارة (تحليل النصيوص وفق بنيتها)، ومهارة (تحليل مضمهون النص المقروء) متوسطاً، أما مستواهم في مهارة (إدراك الكلمات الجديدة واستراتيجيات

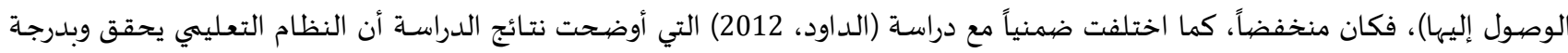

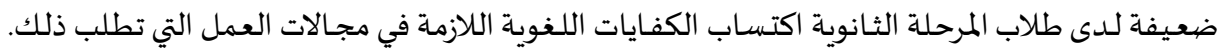

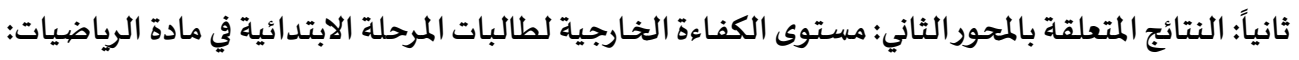

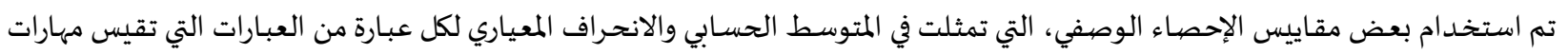
خريجات المرحلة الابتدائية في مادة الرياضيات في المدارس التابعة لمكتب تعليم شمال المدينة المنـورة من وجهاة نظر معلمات المرحلة المتوسطة.

\begin{tabular}{|c|c|c|c|c|c|c|}
\hline التقدير & الترتيب & المئوية & المسابي & المعياري & 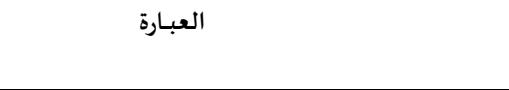 & b \\
\hline 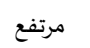 & 3 & $70.9 \%$ & 3.543 & 0.9079 & تمتلك الطالبة المهارة لحل العمليات الحسابية. & 1 \\
\hline 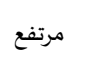 & 2 & $75.5 \%$ & 3.776 & 0.6989 & تقوم الطالبة بحل مسائل باستخدام العمليات الرياضية. & 2 \\
\hline 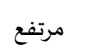 & 6 & $70.4 \%$ & 3.518 & 0.9554 & تستخدم الطالبة قواعد القسمة بشكل جيد. & 3 \\
\hline 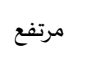 & 9 & $69.3 \%$ & 3.466 & 0.8488 & تحول الطالبة وحدات النظام المتري بشكل جيد. & 4 \\
\hline 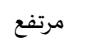 & 1 & $80.0 \%$ & 4.000 & 0.8129 & تصنف الطالبة المثلثات والأشكال الرباعية. & 5 \\
\hline 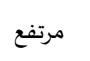 & 5 & $70.5 \%$ & 3.526 & 0.8793 & تعرِف الطالبة الكسور الاعتيادية. & 6 \\
\hline 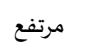 & 8 & $70.2 \%$ & 3.509 & 0.8392 & تقوم الطالبة بقراءة البيانات الرياضية وتفسيرها. & 7 \\
\hline 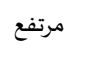 & 10 & $69.0 \%$ & 3.448 & 0.8978 & تمتلك القدرة على تقريب الكسور العشرية. & 8 \\
\hline 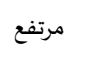 & 4 & $70.7 \%$ & 3.534 & 0.9907 & تجمع وتطرح الكسور العشرية. & 9 \\
\hline 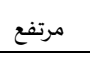 & 7 & $70.3 \%$ & 3.517 & 0.8596 & تستطيع الطالبة كتابة الكسور غير الفعلية بشكل جيد. & 10 \\
\hline \multicolumn{2}{|c|}{$71.7 \%$} & $\% 71.7$ & 3.584 & 0.4587 & المعدل العام محور الرياضيات & \\
\hline
\end{tabular}

يتضح من الجدول (7) أن متوسطات عبارات المحـور الثاني: الرياضيات تراوحت بين (3.448- 4.000) وفق مقياس ليكرت الخماسي وبنسبة

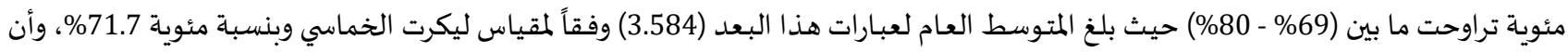

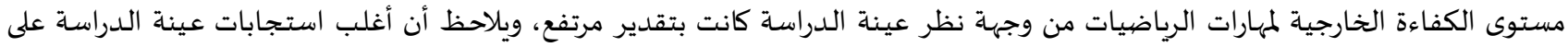

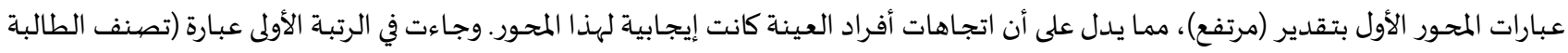
المثلثات والأشكال الرباعية) بمتوسط حسابي بلغ (4.00) وانحراف معياري (0.8129) وبنسبة مئوية 80\%، بينما جاء في الرتبة الأخيرة عبارة (تمتلك

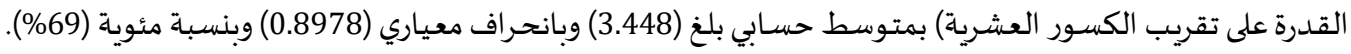

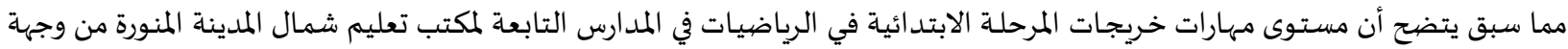

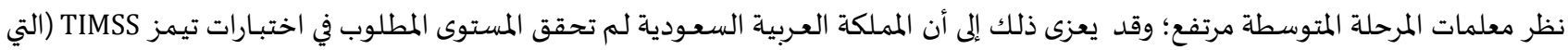

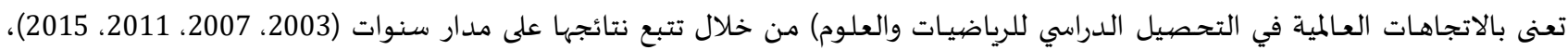

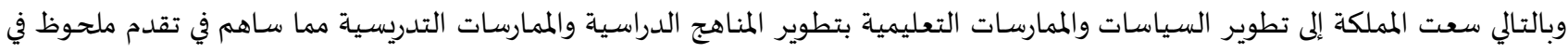
مؤشرات التحصيل الدراسي جميعها مقارنة مع عام 2015، حيث ارتفع متوسط درجات الطلبة في عام 2019 عن عام 2015؛ وكان اللافت في نتائج 
الصف الرابع حصول السعودية على المركز الأول دولياً من حيث الفارق الكبير في النتائج بين الجنسين، حيث تقدمت الطالبات السعوديات في نتائج

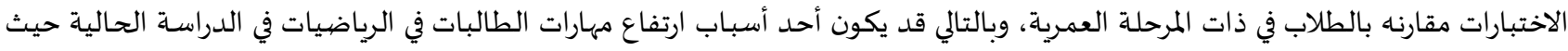

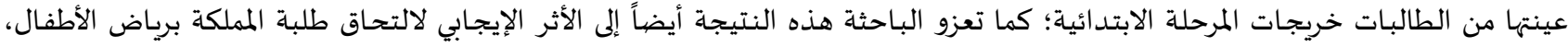

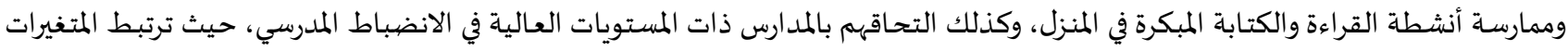

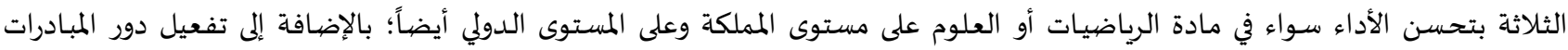
والمؤتمرات والبرامج التي تهدف إلى تطوير تعليم وتعلم العلوم والرياضيات مثل: برنامج تنمية القدرات البشرية في رؤية 2030 والذي يهدف إلى إلى تعزيز

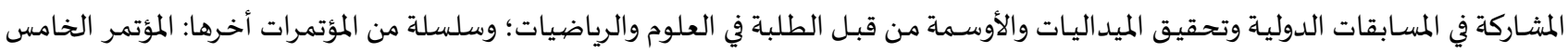

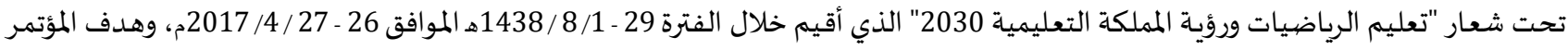

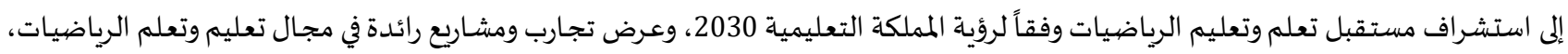

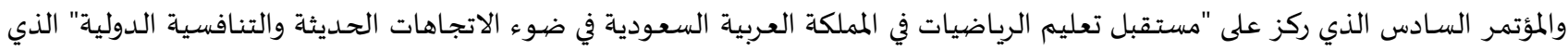

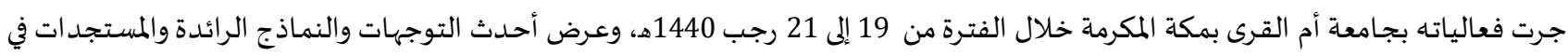

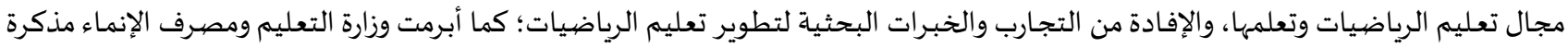

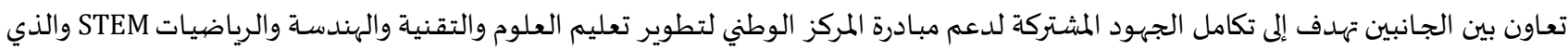

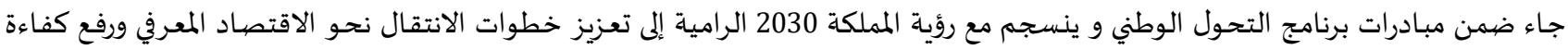

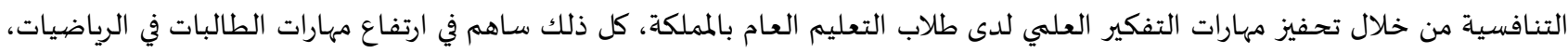

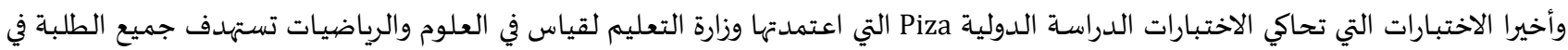

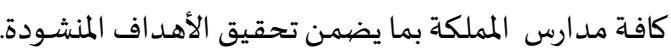

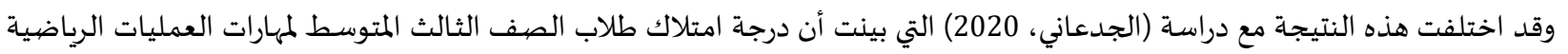

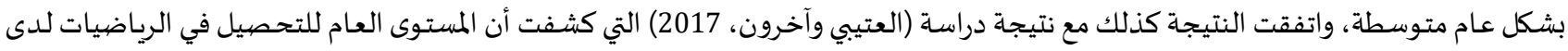

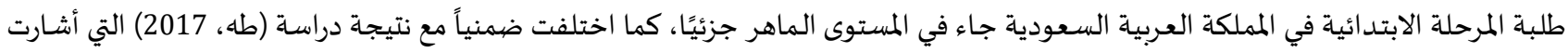

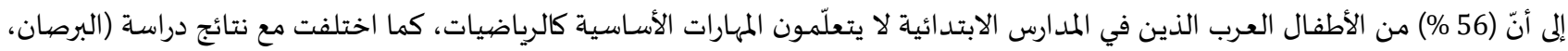

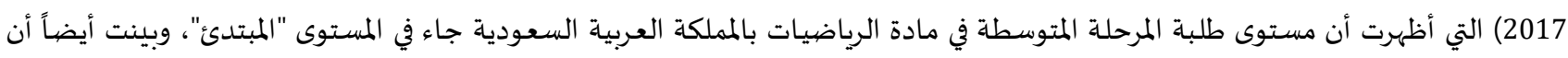
تحصيل الطلبة جاء في المستوى المبتدئ لجميع مجالات المحتوى الرياضي باستثناء مجال الهندسية الذي جاء فئي في المستوى "الماهر جزئيا"، وكان التحصيل في مجال القياس هو الأقل. وعلى مستوى الأداة ككل يوضح الجدول (8) مستوى الكفاءة الخارجية لطالبات المرحلة الابتدائية في في مادتي لغتي الجميلة والرياضيات في

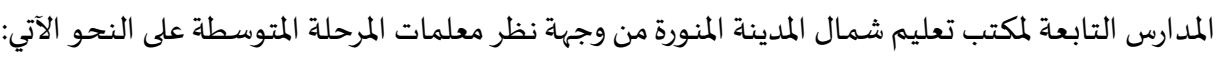

جدول (8): المتوسطات الحسابية والإنحر افات المعيارية والنسبة المئوية لمستوى الكفاءة الخارجية لطالبات المرحلة الابتدائية في (مادة لغتي الجميلة، ومادة الرياضيات)

\begin{tabular}{|c|c|c|c|c|c|}
\hline التقدير & النسبة المئوية & المستوسطي & المعياري & مجموع الأوزان & المحور \\
\hline 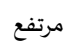 & $\% 73$ & 3.648 & 0.4269 & 481.6 & المعدل العام لمحور لغتي الجميلة \\
\hline مرتفع مرتع & $\% 71.6$ & 3.584 & 0.4587 & 415.7 & المعدل العام لمحور الرياضيات \\
\hline مرتفع & $\% 72.3$ & 3.616 & ئية & 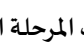 & مستوى الكفاءة الخارجية (مهار \\
\hline
\end{tabular}

يتضح من الجدول (8) أن التحليل الكمي لنتائج الدراسة أثبت أن نسبة تحقق الكفاءة الخارجية لطالبات المرحلة الابتدائية في (لغتي الجميلة،

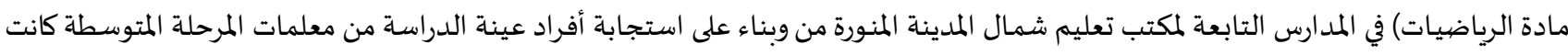
بتقدير مرتفع وبمتوسط حسابي (3.616) وبنسبة مئوية (72.3\%). وقد تعزى هذه النتيجة إلى البرامج والمباردرات ذات العلاقة المباشرة بالمنظومة

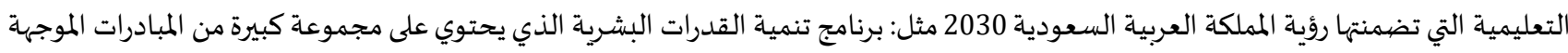
للمرحلة الابتد ائية وتركز على القيم والمهارات الأساسية، مثل اللغة العربية والرياضيات وغيرها من المهارات، والاهتمام بأن يحرز الطلاب نتائج متقدمة

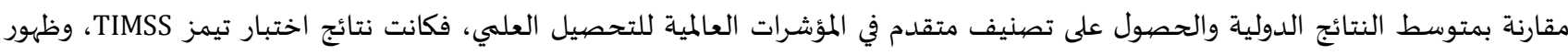

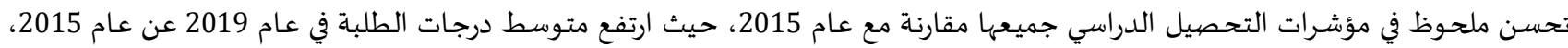
لذلك تعتبر الباحثة هذه النتيجة حصيلة هذا الاهتمام بالعلم وكفاءة التعليم العام، ورؤية 2030 بما فيها من برامج ومبادرات. 
وقد اتفقت هذه النتيجة مع دراسة (الشوابكة وعبابنه، 2020) التي أظهرت أن درجـة الكفاءة الخارجية لكلية الآثار والسياحة في الجامعة

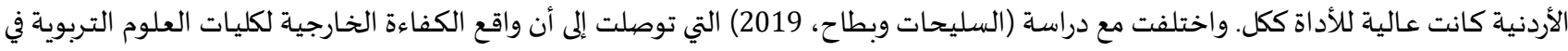

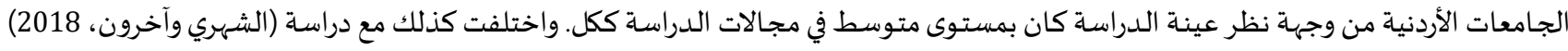

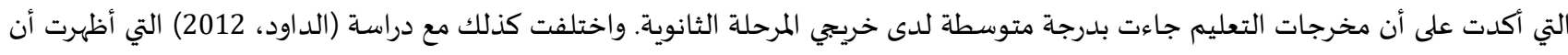

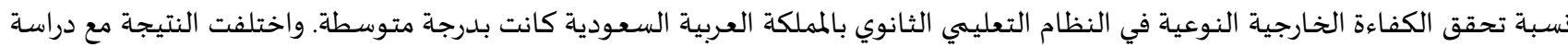
(Qutb, 2016)

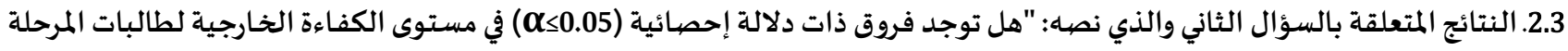
الابتدائية في (مادة لغتي الجميلة، ومادة الرياضيات) في المدارس التابعة لمكتب تعليم شمال المدينة المنورة من وجهة نظر معلمات المرحلة

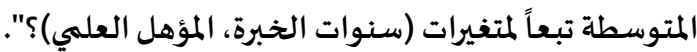
وقد تم عرض النتائج المتعلقة بكل متغير على حدة على النحو التالي: أولاً: النتائج المتعلقة بمتغيرسنوات الخبرة:

تم استخدام تحليل التباين الأحادي (One Way ANOVA) وذلك للوقوف على مستوى الكفاءة الخارجية لطالبات المرحلة الابتدائية في (مادة

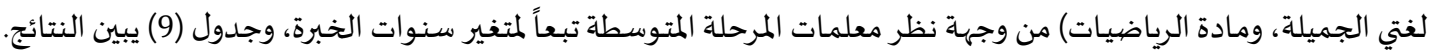
تم استخراج قيمة "ف" والدلالة المعنوية لجميع المحاور والدرجة الكلية للاستبانة، باستخدام تحليل التباين الأحادي (One Way ANOVA) طبقاً لمتغير سنوات الخبرة وفق الآتي:

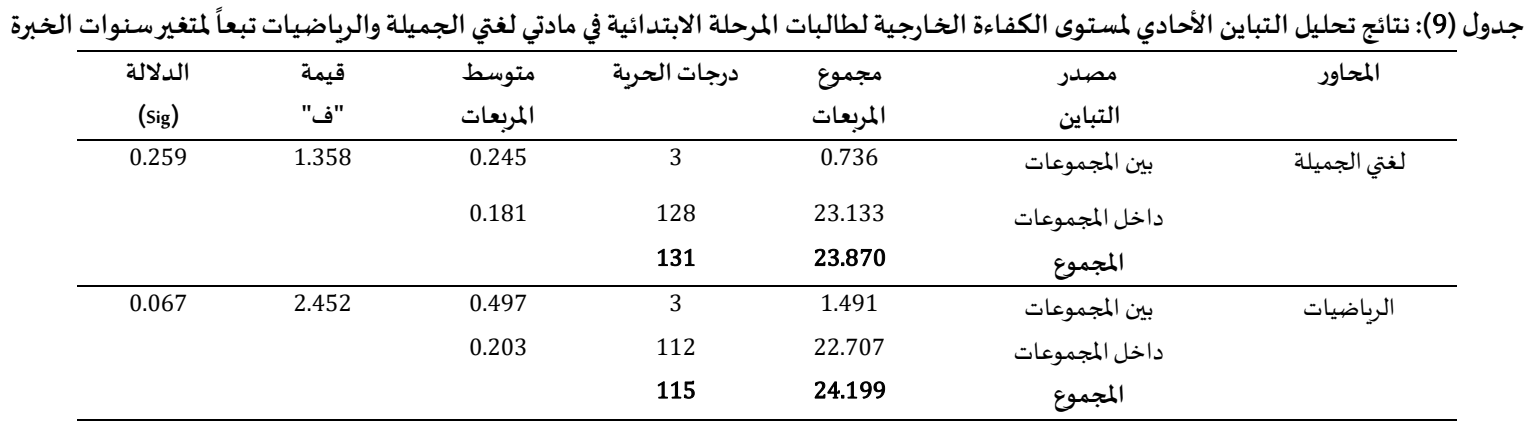

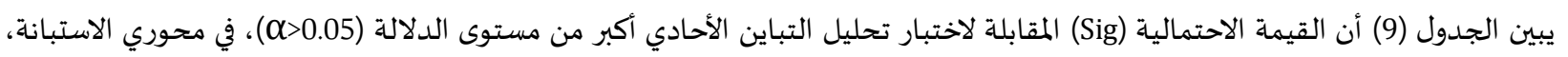
وبذلك يمكن استنتاج عدم وجود فروق ذات دلالة إحصائية بين متوسطات تقديرات عينة الدراسة حول الكفاءة الخارجية للتعليم الابتدائي في

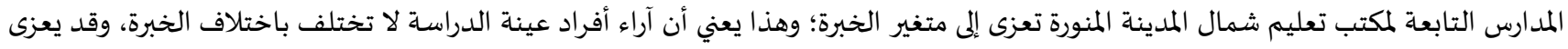

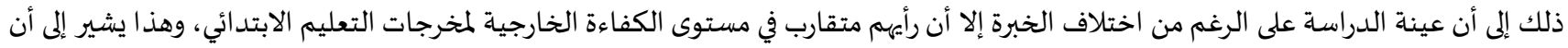

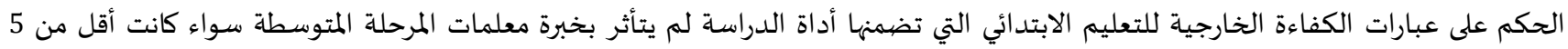

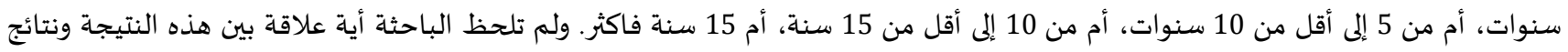
الدراسات السابقة؛ وذلك لاختلاف مجتمع الدراسـة وعينتها، إضافة إلى أن هذه الدراسة بحثت في مستوى الكفاءة الخارجية للمرحلة الإبتدائية وهذا لـألم يتم بحثاه في الدراسـات السابقة التي تم الاطلاع عليها.

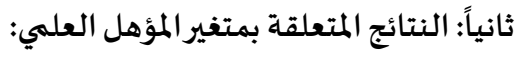
تم استخدام اختبار اختبار "T test" لعينتين مستقلتين، وذلك للوقوف على مسئلى مستوى الكفاءة الخـارجية لطالبات المرحلة الابتدائية في (مادة لغتي الجميلة، ومادة الرياضيات) من وجهة نظر معلمات المرحلة المتوسطة تبعاً لمتغير المؤهل العلمي، وجدول (10) يبين النتائج. جدول (10): نتائج تحليل "T test" طبقاً لمتغير المؤهل العلهي 
يبين الجدول (10) أن القيمة الاحتمالية (Sig) في محور لغتي الجميلة (0.420) وهي اكبر من (0.05)، وأن قيمة "ت" (0.824) المحسبوبة وهي أقل

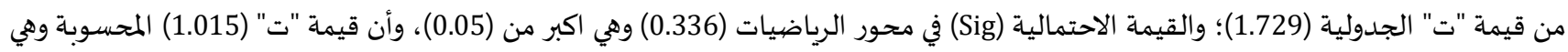

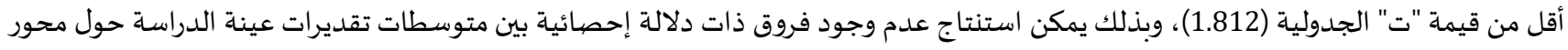

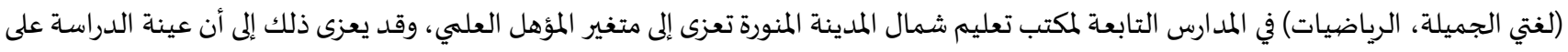

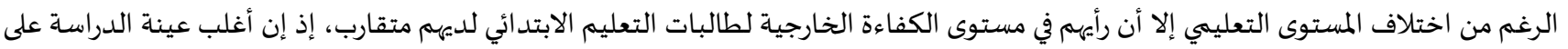

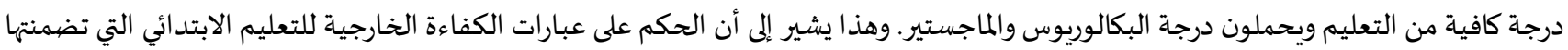
أداة الدراسة لم يتأثر بمؤهل معلمات المرحلة المتوسطة سواء كان بكالوريوس، أم ماجستير فأعلى ولم تلحظ الباحثة أية علاقة بين هذه التهاتئ النتيجة ونتائج

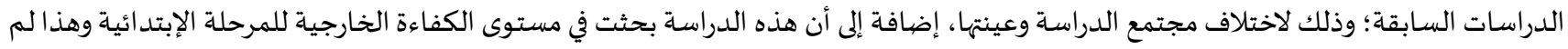

يتم بحثاه في الدراسـات السابقة التي تم الاطلاع عليها.

3.3. التوصيات والمقترحات:

في ضوء النتائج التي توصلت إلهها الدراسـة الحالية لكفاءة مخرجات التهات التعليم الابتدائي فما زال الأمل في نتائج أفضل مستقبلاً لمواكبة الطموحات، والإمكانات المتاحة للتعليم، لذلك توصي وتقترح الباحثة بما يلي:

استمـرار ومتابعة دعم السياسات والمشـروعات والبرامج التي ستسهم في تحقيق المزيد من النجاحات للتحسّن مستقبلاً في الاختبارات الدولية في لغتي الجميلة والرياضيات.

تعديل الخطط الدراسية لزيادة عدد حصص لغتي الجميلة والرياضيات، والاستمرار في عمليات تطوير المناهج، والمعارف والمهارات للطلبة في القراءة والكتابة والرياضيات. الاستفادة من نتائج اختبارات الفاقد التعليمي لمادة لغتي الجميلة والرياضيات في المدارس لخلق روح التنافسية بينهم.

احتسـاب المعدل تراكمي لاجتياز الصفوف (4، 5، 6)؛ وذلك لخلق حس المسؤولية بين الأسرة والطالب والمدرسـة. الحرص على زيادة نسبة الالتحاق برياض الأطفال، لما له من أثار إيجابية على مرحلة التعليم العام.

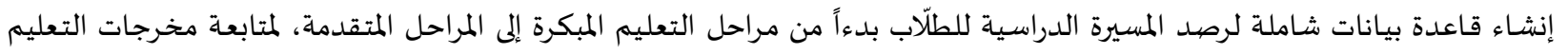

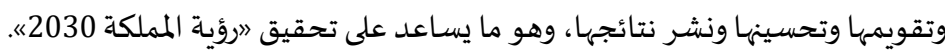
وضع معايير ومؤشـرات لقياس مخرجات التعليم العام ومراجعتها سنوياً. إجراء دراسـة تقويمية شـاملة للتجربة التعليمية الموجودة بالفعل بالتعليم الابتدائي. إجراء دراسة مماثلة للدراسة الحالية تتمثل في الكفاءة الخارجية للتعليم الابتدائي في مناطق مختلفة من المملكة. إجراء دراسـة لقياس الكفاءة الخارجية على مستوى التعليم العام في المملكة العربية السعودية. إجراء دراسات للكفاءة الخارجية للتعليم الجامعي في تخصصات مختلفه.

1. البرصان، إسماعيل سلامة؛ وآخرون (2017). مستوى تحصيل طلبة المرحلة المتوسطة في مادة الرياضيات وفق مشروع تطوير الرياضيات والعلوم

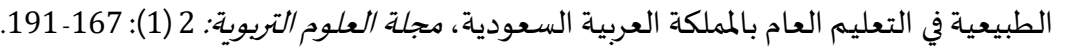

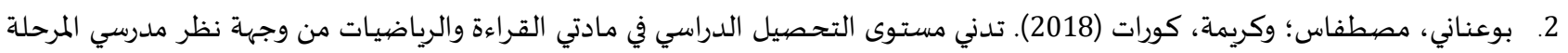
الابتدائية، المجلة الدولية التوبوية المتخصصية: 7 (4): 132- 176.

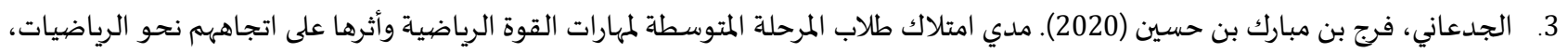

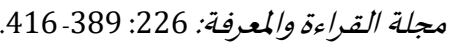

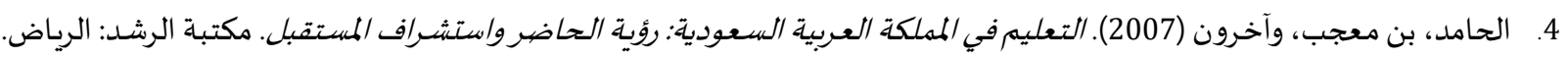
5. الحامد، محمد (1428). التعليم في المملكة العربية السعودية رؤية الحاضر واستشراق المستقبل.(ط 1)، السعودية: مكتبة الرشد.

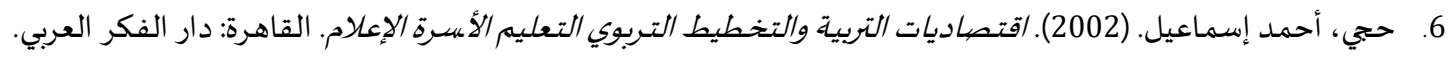

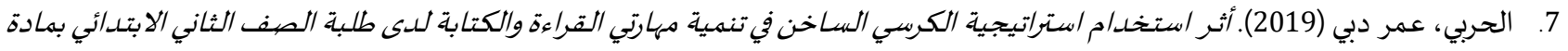
اللغة العببية في دولية الكويت، (رسالة ماجستير غير منشورة)، جامعة آل البيت، الأردن. 
8. الحربي، فهد؛ والقحطاني، فيصل. (2017). المقدرة القرائية وفق المعايير الدولية للطلبة في الصف الرابع الابتدائي قراءة لنتائج مشاركة المملكاة العربية السعودية في اختبار القراءة الدولي" بيرلز" ، ورقة عمل، وكالة الوزارة لتعليم البنين، السعودية.

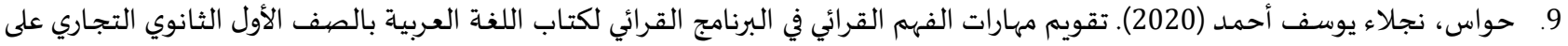

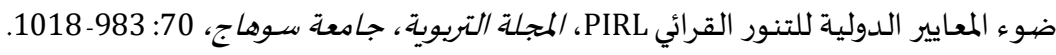

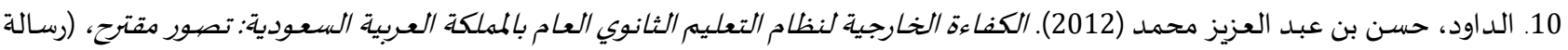
دكتوراه غير منشـورة) ، جامعة الأمام بن سعود الإسلاميـة، الرياض.

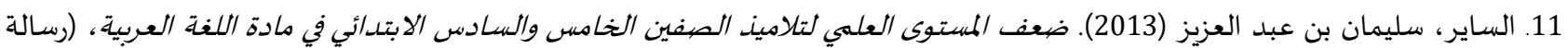
ماجستير غير منشورة)، جامعة القصيم، المملكة العربية السعودية.

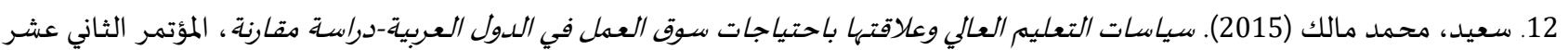
لرابطة التربية الحديثة، السياسات التعليمية في الوطن العربي، كلية التربية، جامعة المنصيورة، المجلد الأول.

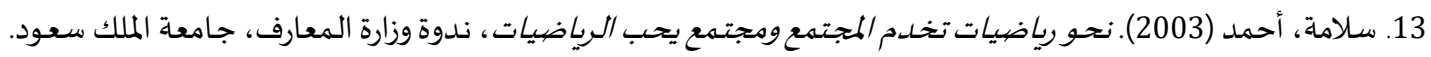
14. السليحات، وعد أحمد، وبطاح، أحمد محمد (2019). تصور مقترح لتحسين الكفاءة الخارجية لكليات العلوم التربوية في الجامعات الأردنية،

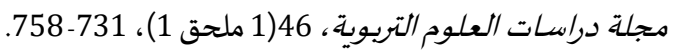

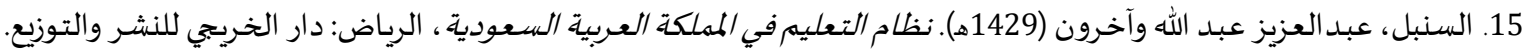

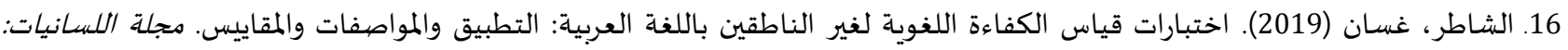
.75-41:(1)25

17. شحادة، فواذ حسن إبراهيم (2016). مستوى تحصيل طلبة المملكة العربية السعودية في الرياضيات والعلوم وفق نتائج الدراسـات الدولية

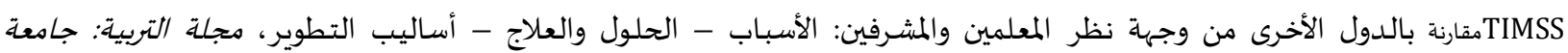
الأزهر، 169 (1): 326- 320

18. الشنقيطي، إمامة محمد (2020). فاعلية برنامج تدريبي في توعية معلمات اللغة العربية بالممارسات المثلى لرفع المقدرة القرائية للطلاب وفق

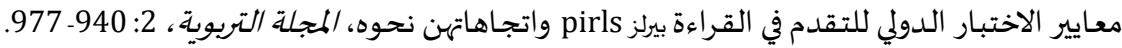

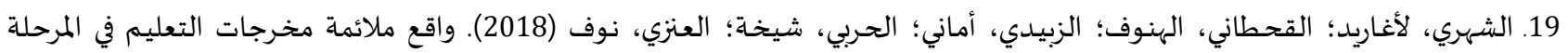

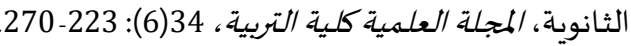

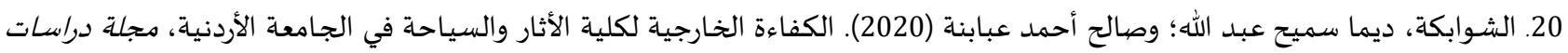

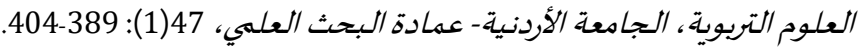

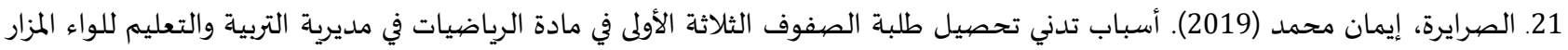

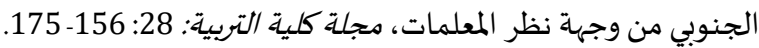

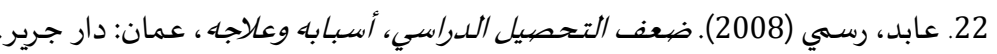

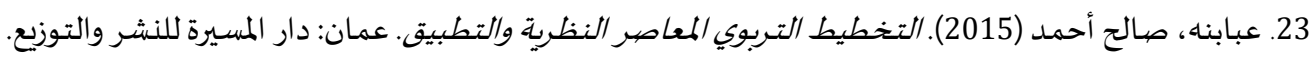
24. عبد الجواد، إياد (2016). برنامج تدريبي لغوي لتنمية كفاءة الفهم اللغوية لغريب بعض مفردات القرآن الكريم لدى طالبات اللغة العربية

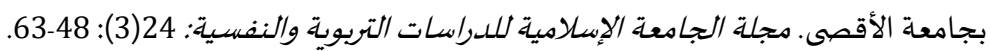

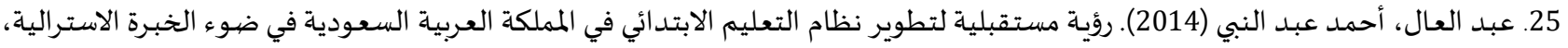
المجلة التسبوية: 35: 157-232.

26. عبد العال، عنتر محمد أحمد (2010). الكفاءة الداخلية للسنة التحضيرية بجامعاة حائل في المملكة العربية السعودية، المحجلة العببية لضهمان

جودة التعليم الجامعي: 5: 46-73-73.

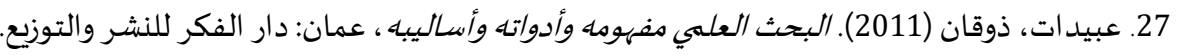

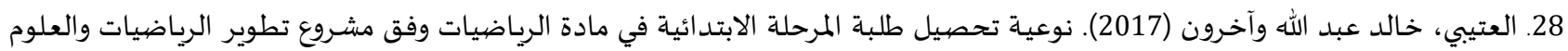

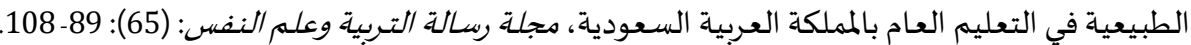
29. أبو عطايا، أشرف، وأبو حمادة، إبراهيم (2019). فاعلية برنامج مقترح قائم على نظرية التعلم المستند إلى جانبي الدماغ لتنمية التحصيل في

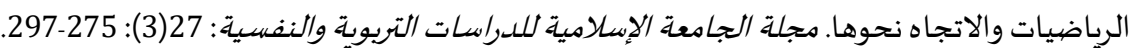
30. العقيل، عبد الله عقيل (2005). سياسـة التعليمرونظامه في المملكة العربية السعودية ، الرياض: مكتبة الرشدـد. 


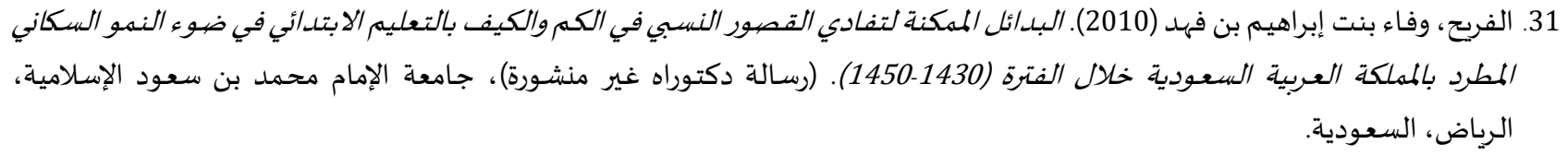

1. Agasisti, T. (2017). Management of higher education institutions and the evaluation of their efficiency and performance. Tertiary Education and Management, 23 (3): 187-190. https://doi.org/10.1080/13583883.2017.1336250

2. Burney, N., \& Mohammed, O. (2002). The efficiency of the public education system in Kuwait. The Social Science Journal, 39(2): 277-286. https://doi.org/10.1016/s0362-3319(02)00168-4

3. Clements, D., Fuson, K., \& Sarama, J. (2017). The research-based balance in early childhood mathematics: A response to common core criticisms. Early Childhood Research Quarterly, 40: 150-162. https://doi.org/10.1016/j.ecresq.2017.03.005

4. Eisemon, Thomas Owen. (2007). Benefiting from Basic Education in Developing Countries: A Review of Research on the External Efficiency of Educational Investments. Special Studies in Comparative Education, Number Twenty, Studies in Comparative Education, Number Twenty. Institution State Univ. of New York, Buffalo. Comparative Education Center.

5. Freitas, M., Flach, L., Mattos, L., Hammes, D. (2017). Determinants of efficiency in education in public expenditure: Crosscountry perspective. Paper presented at the Conference of International Institute of Costs \& 4th Transatlantic Conference of Accounting, Auditing, Financial, Control and Costs Control.

6. Haile, H. (2009). A study on the factors affecting the external efficiency of TVET colleges of Addis Ababa. (A Master's thesis), the School of Graduate Studies, Addis Ababa University.

7. Holm-Nielsen, L. (2011). Challenges for Higher Education Systems. International Conference on Higher Education Reform. Jakarta, August 15.

8. Jimenez, B., \& Saunders, A. (2019). Increasing efficiency in mathematics: Teaching subitizing to students with moderate intellectual disability. Journal of Developmental and Physical Disabilities, 31(1): 23-37. https://doi.org/10.1007/s10882-0189624-y

9. King, Y., \& Purpura, D. (2021). Direct numeracy activities and early math skills: Math language as a mediator. Early Childhood Research Quarterly, 54: 252-259. https://doi.org/10.1016/j.ecresq.2020.09.012

10. Popat \& others (2017). PIRLS for Teachers: A review of practitioner engagement with international large-scale assessment results, Progress in International Reading Literacy Study: PIRLS for Teachers.

11. Qutb, Rasha. (2016). Analyzing the External and Internal Efficiency Considerationsin https://www.academia.edu/11410102/Education_Outcomes_in_the_Arabian_Gulf.

12. Sekreter, G. (2018). The classroom management strategies for the efficiency of mathematics teaching-learning process: Everything you need. International Journal of Social Sciences \& Educational Studies, 5(1): 85-95. https://doi.org/10.23918/ijsses.v5i1p85

13. Somi. (2020). Economics of Education: What are the different types of efficiency and how do they relate to education? https://mysominotes.wordpress.com/2017/09/23/economics-of-education-what-are-the-different-types-of-efficiency-and-how-do-theyrelate-to-education/

14. Tupe, N. (2015). Multimedia scenario-based learning programme for enhancing the English Language efficiency among primary school students. International Journal of Instruction, 8(2): 125-138. https://doi.org/10.12973/iji.2015.8210a 
ثالثاً: المراجع الإلكترونية:

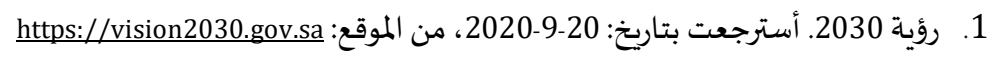

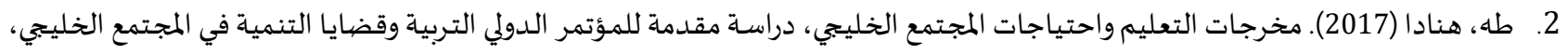

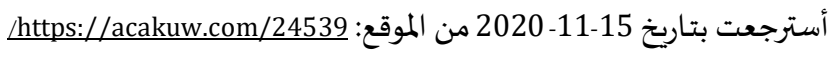

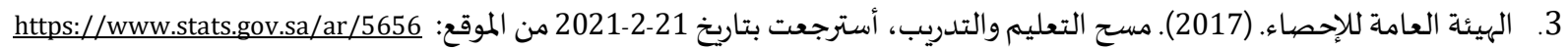

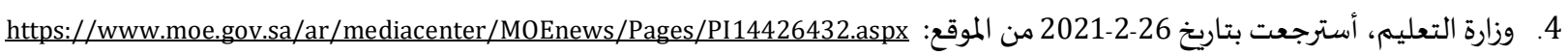

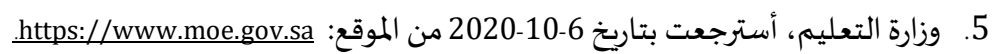


المجلة الدولية للدراسـات التربوية والنفسية

International Journal of Educational \& Psychological Studies (EPS)

Journal Homepage: https://www.refaad.com/views/EPSR/Home.aspx

\title{
The external efficiency of primary education in schools affiliated to the North Madinah Education Office from the point of view of middle school teachers
}

\author{
Haifa Souiad Al-Oufi \\ Master's in Education Economics and Planning, Ministry of Education, KSA \\ haifa2359@gmail.com
}

Received : 7/7/2021 Revised : 20/7/2021 Accepted : 10/8/2021 DOI : https://doi.org/10.31559/EPS2021.10.3.6

Abstract: The study aimed to identify the level of external competence of female students graduating from the primary stage by identifying the level of mathematics skill and my beautiful language they have in the middle schools affiliated with the Education Office north of Madinah. The study adopted the analytical descriptive curriculum. The study community consisted of middle school teachers specializing in (My Beautiful Language, Mathematics) in the schools affiliated to the Education Office north of Medina, which numbered 299 female teachers. The sample of the study to which the questionnaire was applied consisted of 266 teachers. The study found that the skills level of primary school graduates in (my beautiful language, mathematics) from the point of view of the study sample was high. The study also found that there were no statistically significant differences between the averages of the study population's estimates of the external efficiency of primary education in the schools affiliated to the North Madinah Education Office due to the variable (experience- academic qualification). In light of the results, the researcher recommended the importance of reviewing the study plans and working to increase the number of classes for the language of beauty and mathematics. She also recommended using the results of the educational loss tests for the subject of my beautiful language and mathematics in schools to create a spirit of competitiveness among them and to establish a comprehensive data base to monitor the academic progress of students in the different educational stages and to work on developing indicators to measure the outputs of public education and reviewing them annually Calculating a GPA for passing grades $(4,5$, and 6$)$ is important in order to create a sense of responsibility among the family, the student and the school, the keenness to increase the enrollment rate in kindergarten because of its positive effects on the general education stage, and to set standards and indicators to measure the outputs of general education and review them annually.

Keywords: external competence; primary education; schools; Medina.

\section{References:}

1. 'babnh, Salh Ahmd (2015). Altkhtyt Altrbwy Alm'asr Alnzryh Walttbyq. 'man: Dar Almsyrh Llnshr Waltwzy'.

2. 'abd, Rsmy (2008). D'f Althsyl Aldrasy, Asbabh W'lajh, 'man: Dar Jryr.

3. 'bd Aljwad, Eyad (2016). Brnamj Tdryby Lghwy Ltnmyh Kfa'h Alfhm Allghwyh Lghryb B'd Mfrdat Alqran Alkrym Lda Talbat Allghh Al'rbyh Bjam't Alaqsa. Mjlt Aljam'eh Aleslamyh Lldrasat Altrbwyh Walnfsyh: 24(3): 48-63.

4. 'bd Al'al, Ahmd 'bd Alnby (2014). R'yh Mstqblyh Lttwyr Nzam Alt'lym Alabtda'y Fy Almmlkh Al'rbyh Als'wdyh Fy Dw' Alkhbrh Alastralyh, Almjlh Altrbwyh: 35: 157-232.

5. 'bd Al'al, 'ntr Mhmd Ahmd (2010). Alkfa'h Aldakhlyh Llsnh Althdyryh Bjam't Ha'l Fy Almmlkh Al'rbyh Als'wdyh, Almjlh Al'rbyh Ldman Jwdt Alt'lym Aljam'y: 5: 46-73.

6. 'bydat, Dwqan (2011). Albhth Al'Imy Mfhwmh Wadwath Wasalybh, 'man: Dar Alfkr Llnshr Waltwzy'.

7. Al'qyl, 'bd Allh 'qyl (2005). Syash Alt'lym Wnzamh Fy Almmlkh Al'rbyh Als'wdyh, Alryad: Mktbt Alrshd.

8. Abw 'taya, Ashrf, Wabw Hmadh, Ebrahym (2019). Fa'lyt Brnamj Mqtrh Qa'm 'la Nzryt Alt'lm Almstnd Ela Janby Aldmagh Ltnmyh Althsyl Fy Alryadyat Walatjah Nhwha. Mjlt Aljam'h Aleslamyh Lldrasat Altrbwyh Walnfsyh: 27(3): 275-297.

9. Al'tyby, Khald 'bd Allh Wakhrwn (2017). Nw'yh Thsyl Tlbt Almrhlh Alabtda'yh Fy Madh Alryadyat Wfq Mshrw' Ttwyr Alryadyat Wal'lwm Altby'yh Fy Alt'lym Al'am Balmmlkh Al'rbyh Als'wdyh, Mjlt Rsalh Altrbyh W'lm Alnfs: (65): $89-108$. 
10. Albrsan, Esma'yl Slamh؛ Wakhrwn (2017). Mstwa Thsyl Tlbt Almrhlh Almtwsth Fy Madt Alryadyat Wfq Mshrw' Ttwyr Alryadyat Wal'lwm Altby'yh Fy Alt'lym Al'am Balmmlkh Al'rbyh Als'wdyh, Mjlt Al'lwm Altrbwyh: 2 (1): 167 - 191.

11. Bw'nany, Mstfas, Wkrymh, Kwrat (2018). Tdny Mstwa Althsyl Aldrasy Fy Madty Alqra'h Walryadyat Mn Wjht Nzr Mdrsy Almrhlh Alabtda'yh, Almjlh Aldwlyh Altrbwyh Almtkhssh: 7 (4): 132- 176.

12. Aldawd, Hsn Bn 'bd Al'zyz Mhmd (2012). Alkfa'h Alkharjyh Lnzam Alt'lym Althanwy Al'am Balmmlkh Al'rbyh Als'wdyh: Tswr Mqtrh, (Rsalt Dktwrah Ghyr Mnshwrh), Jam't Alamam Bn S'wd Aleslamyh, Alryad.

13. Alhamd, Bn M'jb, Wakhrwn (2007). Alt'lym Fy Almmlkh Al'rbyh Als'wdyh: R'yt Alhadr Wastshraf Almstqbl. Mktbt Alrshd: Alryad.

14. Alhamd, Mhmd (1428). Alt'lym Fy Almmlkh Al'rbyh Als'wdyh R'yt Alhadr Wastshraq Almstqbl.(T1), Als'wdyh: Mktbh Alrshd.

15. Hjy, Ahmd Esma'yl. (2002). Aqtsadyat Altrbyh Waltkhtyt Altrbwy Alt'lym Alasrh Ale'lam. Alqahrh: Dar Alfkr Al'rby.

16. Alhrby, 'mr Dby (2019). Athr Astkhdam Astratyjyh Alkrsy Alsakhn Fy Tnmyt Mharty Alqra'h Walktabh Lda Tlbt Alsf Althany Alabtda'ey Bmadh Allghh Al'rbyh Fy Dwlt Alkwyt, (Rsalt Majstyr Ghyr Mnshwrh), Jam't Al Albyt, Alardn.

17. Alhrby, Fhd, Walqhtany, Fysl. (2017). Almqdrh Alqra'yh Wfq Alm'ayyr Aldwlyh Lltlbh Fy Alsf Alrab' Alabtda'y Qra't Lnta'j Msharkt Almmlkh Al'rbyh Als'wdyh Fy Akhtbar Alqra'h Aldwly "Byrlz", Wrqh 'ml, Wkalt Alwzarh Lt'lym Albnyn, Als'wdyh.

18. Hwas, Njla' Ywsf Ahmd (2020). Tqwym Mharat Alfhm Alqra'y Fy Albrnamj Alqra'y Lktab Allghh Al'rbyh Balsf Alawl Althanwy Altjary 'la Dw' Alm'ayyr Aldwlyh Lltnwr Alqra'y Pirl, Almjlh Altrbwyh, Jam't Swhaj, 70: 983- 1018.

19. Aljd'any, Frj Bn Mbark Bn Hsyn (2020). Mdy Amtlak Tlab Almrhlh Almtwsth Lmharat Alqwh Alryadyh Wathrha 'la Atjahhm Nhw Alryadyat, Mjlt Alqra'h Walm'rfh: 226: 389- 416.

20. S'yd, Mhmd Malk (2015). Syasat Alt'lym Al'aly W'laqtha Bahtyajat Swq Al'ml Fy Aldwl Al'rbyh-Drash Mqarnh, Alm'tmr Althany 'shr Lrabth Altrbyh Alhdythh, Alsyasat Alt'lymyh Fy Alwtn Al'rby, Klyt Altrbyh, Jam't Almnswrh, Almjld Alawl.

21. Alsayr, Slyman Bn 'bd Al'zyz (2013). D'f Almstwa Al'lmy Ltlamyd Alsfyn Alkhams Walsads Alabtda'ey Fy Madh Allghh Al'rbyh, (Rsalt Majstyr Ghyr Mnshwrh), Jam't Alqsym, Almmlkh Al'erbyh Als'ewdyh.

22. Shhadh, Fwad Hsn Ebrahym (2016). Mstwa Thsyl Tlbh Almmlkh Al'rbyh Als'wdyh Fy Alryadyat Wal'lwm Wfq Nta'j Aldrasat Aldwlyh Timssmqarnh Baldwl Alakhra Mn Wjht Nzr Alm'lmyn Walmshrfyn: Alasbab - Alhlwl Wal'laj - Asalyb Alttwyr, Mjlt Altrbyh: Jam't Alazhr,169(1): 326- 370.

23. Alshnqyty, Emamh Mhmd (2020). Fa'lyt Brnamj Tdryby Fy Tw'yh M'lmat Allghh Al'erbyh Balmmarsat Almthla Lrf' Almqdrh Alqra'yh Lltlab Wfq M'ayyr Alakhtbar Aldwly Lltqdm Fy Alqra'h Byrlzpirls Watjahathn Nhwh, Almjlh Altrbwyh, 2: $940-977$.

24. Alshatr, Ghsan (2019). Akhtbarat Qyas Alkfa'h Allghwyh Lghyr Alnatqyn Ballghh Al'rbyh: Alttbyq Walmwasfat Walmqayys. Mjlt Allsanyat: 25(1): 41-75.

25. Alshhry, Lagharyd؛ Alqhtany, Alhnwf, Alzbydy, Amany؛ Alhrby, Shykhh, Al'nzy, Nwf (2018). Waq' Mla'mh Mkhrjat Alt'lym Fy Almrhlh Althanwyh, Almjlh Al'lmyh Klyt Altrbyh, 34(6): 223- 270.

26. Alshwabkh, Dyma Smyh 'bd Allh, Wsalh Ahmd 'babnh (2020). Alkfa'h Alkharjyh Lklyh Alathar Walsyahh Fy Aljam'h Alardnyh, Mjlt Drasat Al'lwm Altrbwyh, Aljam'h Alardnyh- 'madt Albhth Al'lmy, 47(1): 389-404.

27. Slamh, Ahmd (2003). Nhw Ryadyat Tkhdm Almjtm' Wmjtm' Yhb Alryadyat, Ndwt Wzart Alm'arf, Jam't Almlk S'wd.

28. Alslyhat, W'd Ahmd, Wbtah, Ahmd Mhmd (2019). Tswr Mqtrh Lthsyn Alkfa'h Alkharjyh Lklyat Al'lwm Altrbwyh Fy Aljam'at Alardnyh, Mjlt Drasat Al'lwm Altrbwyh, 46(1 Mlhq 1), 731- 758.

29. Alsnbl, 'bdal'zyz 'Ebd Allh Wakhrwn (1429h). Nzam Alt'lym Fy Almmlkh Al'rbyh Als'wdyh, Alryad: Dar Alkhryjy Llnshr Waltwzy'.

30. Alsrayrh, Eyman Mhmd (2019). Asbab Tdny Thsyl Tlbt Alsfwf Althlathh Alawla Fy Madt Alryadyat Fy Mdyryt Altrbyh Walt'lym Llwa' Almzar Aljnwby Mn Wjht Nzr Alm'Imat, Mjlt Klyt Altrbyh: 28: 156- 175. 